Article

\title{
Urban Morphological Change Analysis of Dhaka City, Bangladesh, Using Space Syntax
}

\section{Bayes Ahmed ${ }^{1, *}$, Rakibul Hasan ${ }^{2}$ and K. M. Maniruzzaman ${ }^{3}$}

1 Institute for Risk and Disaster Reduction (IRDR), Department of Earth Sciences, University College London (UCL), Gower Street, London WC1E 6BT, UK

2 Department of Spatial Planning and Development, Umeå University, Umeå 90187, Sweden; E-Mail: rakib121@gmail.com or mura0016@student.umu.se

3 Department of Urban and Regional Planning, College of Architecture and Planning, University of Dammam, P.O. Box 2397, Dammam 31451, Kingdom of Saudi Arabia; E-Mail: kuzzaman@uod.edu.sa

* Author to whom correspondence should be addressed; E-Mail: bayesahmed@gmail.com or bayes.ahmed.13@ucl.ac.uk.

External Editors: Federico Martellozzo and Wolfgang Kainz

Received: 5 June 2014; in revised form: 18 November 2014 / Accepted: 26 November 2014 /

Published: 18 December 2014

\begin{abstract}
This article is based on a study of the morphological changes of Dhaka City, the capital of Bangladesh. The main objective of the research is to study the transformation of urban morphology in Dhaka City from 1947 to 2007. Three sample wards (18, 19 and 72) of Dhaka City Corporation are strategically selected as the study areas. Ward 72 has an indigenous type of organic settlement, whereas ward 19 is a planned area, and ward 18 represents a mixed (both planned and informal) type of settlement. In this research, the transformation of urban settlement pattern is examined through space syntax. The results show that the organic settlements (ward 72) are highly integrated both in terms of the local and global syntactic measures (lowest standard deviation for local and global integration, with the highest intelligibility values), and are more connectivity. The scenario is opposite in the case of planned settlements. The characteristics of mixed areas (ward 18) lie in between the organic and planned settlements. Therefore, in summary, it can be stated that the integration, connectivity and intelligibility measures of Dhaka City are found to be high, medium and low for the indigenous, mixed and planned settlement types; respectively.
\end{abstract}


Keywords: urban morphology; space syntax; settlement pattern; street network; urban planning; GIS; Dhaka

\section{Introduction}

Dhaka, the capital city of Bangladesh, has grown spontaneously without any prior or systematic planning. As the growth of population in Dhaka has been exceptionally high since the 1970s, it has become one of the most populous megacities in the world [1]. The population of this city has increased more than three-fold in the past two decades (Table A1). In the process of urbanization, the physical characteristics of Dhaka City are gradually changing, as open spaces and water bodies are being converted into built-up areas [2]. Therefore, it is necessary to track the morphological changes of Dhaka City - especially the changes in the settlement pattern of the city.

The growth and development of Dhaka can be categorized into six periods, viz. the pre-Mughal period (1205-1610), the Mughal period (1620-1757), the East India Company period (1758-1858), the British colonial period (1858-1947), the Pakistan period (1947-1971), and the Bangladesh period (from 1971 onwards). After the British colonial period, Dhaka City was established as the capital of East Pakistan. Gradually this city became the central point of attraction and people from other districts started migrating to Dhaka. This is why; society radically changed after the British colonial period, and since then Dhaka City underwent drastic changes over the past six decades [3]. Therefore, the focus of this study is the period since 1947.

The physical changes that Dhaka went through were not only in terms of vast territorial expansion, but also through internal physical transformations. The urban built-up area of Dhaka increased by $88.78 \%$ in the past 20 years from 1989 to 2009 (Figure A1) [4]. Vacant plots and open spaces were transformed into built areas, open squares into car parks, and low land and water bodies into reclaimed, built-up land [2]. The enormous growth in population had its impact upon the city's streets, urban pattern, open spaces, environment housing, and various service sectors, as well as upon its social and economic life [3]. In this regard, this research is an attempt to study the transformation of urban morphology of Dhaka City from 1947 to 2007. This kind of research is significant in analyzing how the urban morphology or settlement pattern of a city, that was rated as the least livable in the world (Global Livability Report, the Economist Intelligence Unit, 2012) [5]; changes over time.

\section{Data Collection}

\subsection{Study Area Profile}

In this article, the term "Dhaka City" stands for "Dhaka Metropolitan Area (DMA)", which is located almost at the geographical center of Bangladesh at $23^{\circ} 43^{\prime} 0^{\prime \prime}$ North latitude and $90^{\circ} 24^{\prime} 0^{\prime \prime}$ East longitude (Figure 1a), on the eastern bank of the Buriganga River [4]. DMA covers a total area of about $1530 \mathrm{~km}^{2}$ [3]. The central part of DMA is demarcated as Dhaka City Corporation (DCC), which is approximately $360 \mathrm{~km}^{2}$ in area. There are 92 wards in DCC (Figure 1b). The ward is the smallest electoral unit of urban areas in Bangladesh [3]. 
Figure 1. Location of Dhaka Metropolitan Area (a) in Bangladesh and (b) in Dhaka City Corporation (DCC). Source: (a) Banglapedia, National Encyclopedia of Bangladesh, 2014, and (b) the Capital Development Authority (RAJUK), Dhaka, Bangladesh, 2014.
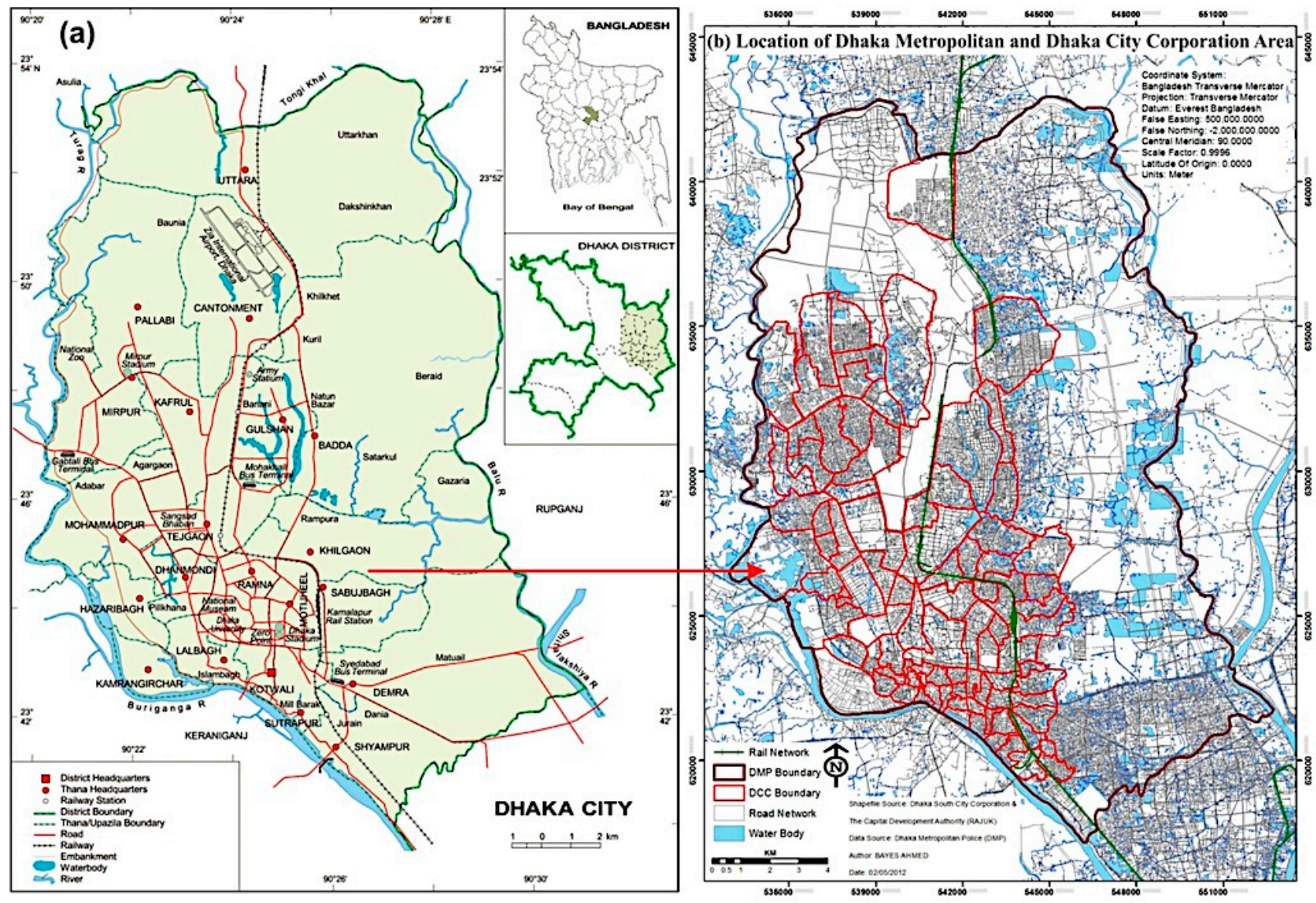

Dhaka has a long history dating back about 400 years [6]. The city went through phases of growth and decline from its beginning as a city with a small population to its current state as a tremendously expanded megacity. Historically, the development of Dhaka City started from the southern river bank in the pre-Mughal period, an area that is now a part of Old Dhaka. Then the city extended to the west and the north during the Mughal and British periods. During the Pakistan period, the development was primarily towards the north, and later it continued rapidly in an unplanned way in every direction [7]. Figure 2 shows the physical development of Dhaka City at different stages of its growth.

\subsection{Selection of Study Areas}

Studies show that at present three distinctive types of urban settlements exist in Dhaka City. These are the indigenous, planned, and informal settlements [8]. The indigenous settlement, commonly called "Old Dhaka", is characterized by its high-density mixed land use pattern, typically ceding the outer layer to commercial uses and retaining the inner part for residential and manufacturing uses. The historic kernel of Old Dhaka retains the traditional features it inherited from the past [8].

An alternative planned or geometric type of development was introduced in Dhaka City in the early 1950s. The street layout of planned areas generally follows a grid-iron pattern with some semi-circular segments. The high space and service standards, and the physical layout of these schemes have an aura 
of modernity. These formal settlements are use-specific, having separate zones for different uses like residential, commercial, industrial, and institutional, etc. [8].

Figure 2. The historical growth of Dhaka City (not to scale). Source: Urban Planning Department, Dhaka City Corporation, 2007.
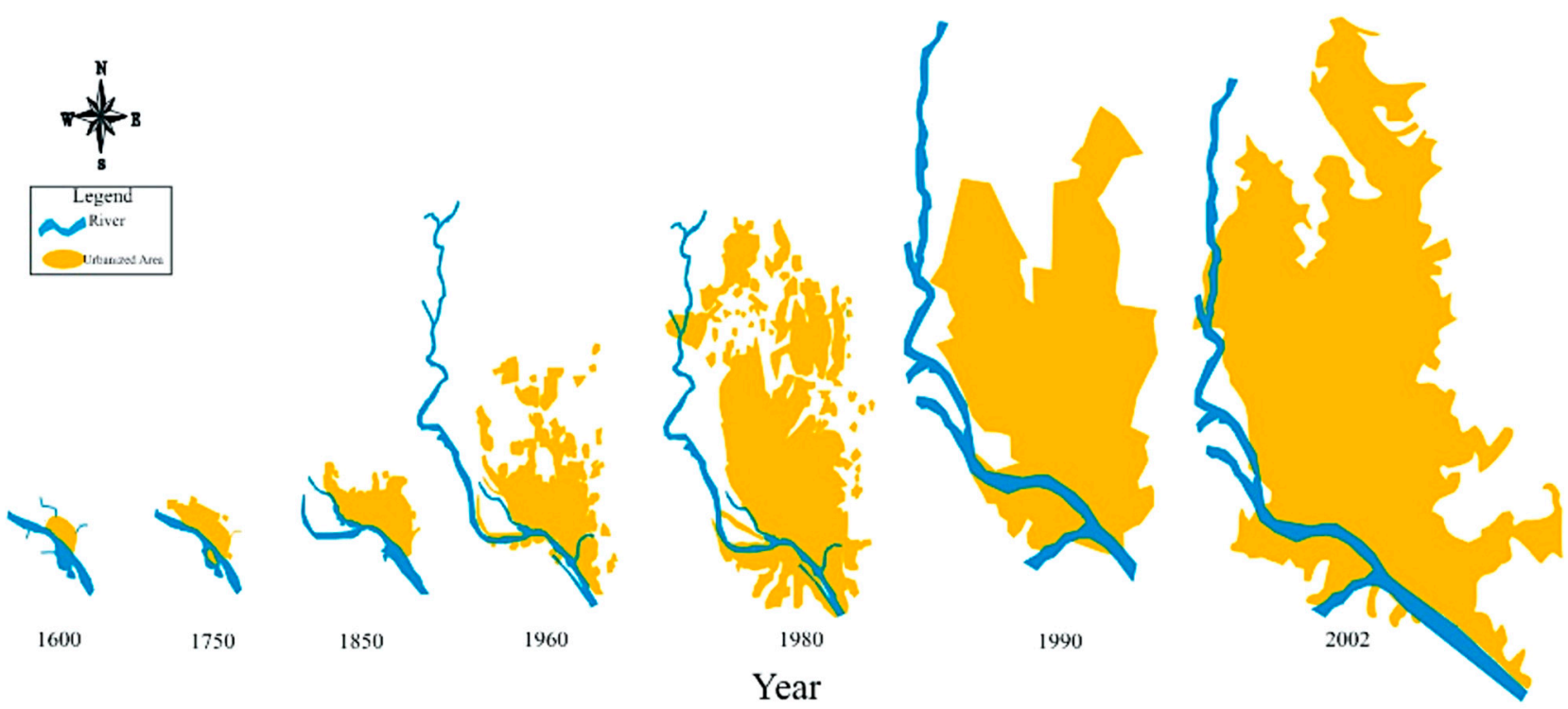

In the newer extensions of Dhaka, outside the historic core, similar organic morphological patterns are prevalent that is being spontaneously developed without any rigid planning framework. In terms of established planning principles, the character of these newer areas is chaotic and sprawling. These are customarily described as "informal" development. These new-generation organic areas are generally developed according to the aspiration of their inhabitants, as in the case of the historic city [9].

It was not possible to analyze the morphological change of DMA, due to time and budget constraints. Therefore, one ward from each type of urban settlements in DCC is selected. The three selected wards from DCC are 18, 19, and 72. Ward 72 (Old Dhaka) represents an area that originated in the pre-Mughal period (1205-1610), whereas ward 19 (Gulshan) was developed as a planned residential area in 1961 [3]. Ward 18 is a more recently developed area and is still growing. It has a combination of both the formal (e.g., Baridhara) and informal (e.g., Shahzadpur and Kalachadpur areas) types of settlements. These three wards represent the spectrum of the urban fabric that exists in Dhaka City. Therefore, analyzing the morphological transformations of these selected three wards will provide an overall idea of the change of settlement patterns in Dhaka City.

The Local Government (City Corporation) Amendment Act (2011) divided DCC as Dhaka South City Corporation (DSCC) and Dhaka North City Corporation (DNCC) on 4 December 2011 [5]. Because of this amendment, DCC was divided into two parts: DSCC and DNCC. But the study intervene area covers both parts of DCC. Therefore, in this article, the common term "DCC" is used in general. Moreover, this paper is following the previous numbering system of the wards.

\subsubsection{Ward 72: Old Dhaka (Indigenous Settlement)}

Ward 72 is located in Kotwali thana (Figure 3). Thana is a spatial unit for police administration in urban areas. Kotwali thana is a part of Old Dhaka. Kotwali thana, area $0.67 \mathrm{~km}^{2}$, is located at $23.706^{\circ} \mathrm{N}$ 
and $90.325^{\circ} \mathrm{E}[2,3]$. Throughout the chronological development of Dhaka City, the urban fabric of Old Dhaka preserved its indigenous morphological characteristic. The organic localities in the old city are distinctive geographical areas with homogenous morphological character [3].

This old settlement is characterized by a pattern of typically narrow streets. Its organic character is particularly distinctive owing to the density of its built-up areas. The narrow streets in the historic part are labyrinthine, and convoluted to an extreme degree in some places. However, a few long stretches of straight streets pass through the residential areas [2,3].

Figure 3. Location of ward 72 (a) in Kotwali thana and; (b) in DCC. Source: (a) Banglapedia, National Encyclopedia of Bangladesh, 2014.

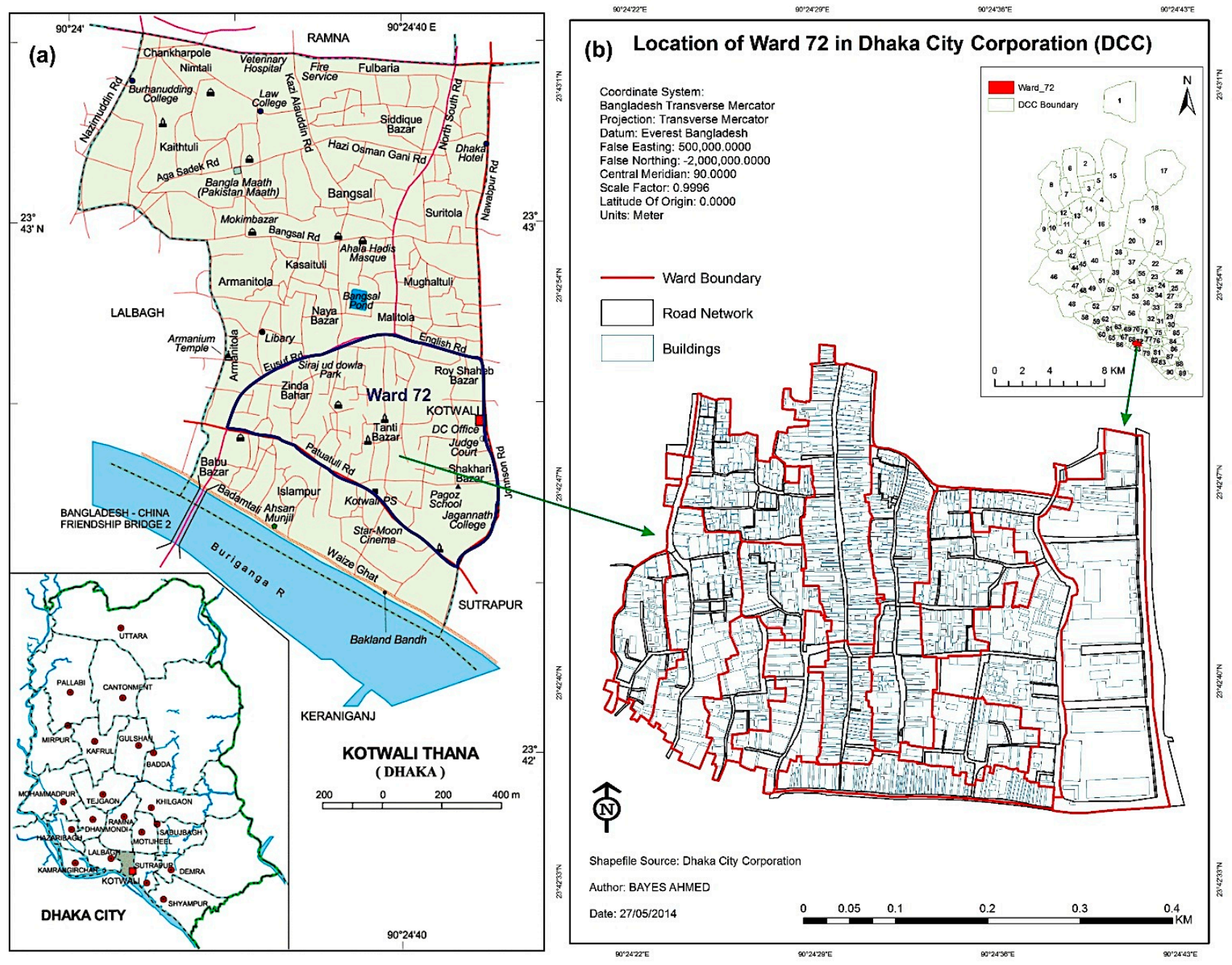

\subsubsection{Ward 19: Gulshan and Banani Model Town (Planned Settlement)}

Gulshan thana was formed in 1972 with an area of $8.85 \mathrm{~km}^{2}$. It consists of both wards 18 and 19, including Gulshan Model Town, Gulshan circle 1 and circle 2, Banani Model Town, Baridhara Diplomatic Zone, and Mohakhali. This thana is bounded by Cantonment and Badda thanas on the north, Tejgaon and Khilgaon thanas on the south, Badda thana on the east, and Kafrul thana on the west (Figure 4). Gulshan was founded as a planned model town in 1961, while the neighboring Banani Model town was founded in 1964 [3]. Gulshan (ward 19) is one of the high-class residential areas in 
Dhaka City. This area was planned and developed in the early sixties to provide residential accommodation for the high and higher-middle income people of Dhaka City. But within the next two decades, the characteristics of its residential area changed. It was gradually invaded by non-residential uses like commercial, administrative, health, and educational, etc. [3].

Figure 4. Location of ward 19 (a) in Gulshan thana and (b) in DCC. Source: (a) Banglapedia, National Encyclopedia of Bangladesh, 2014.

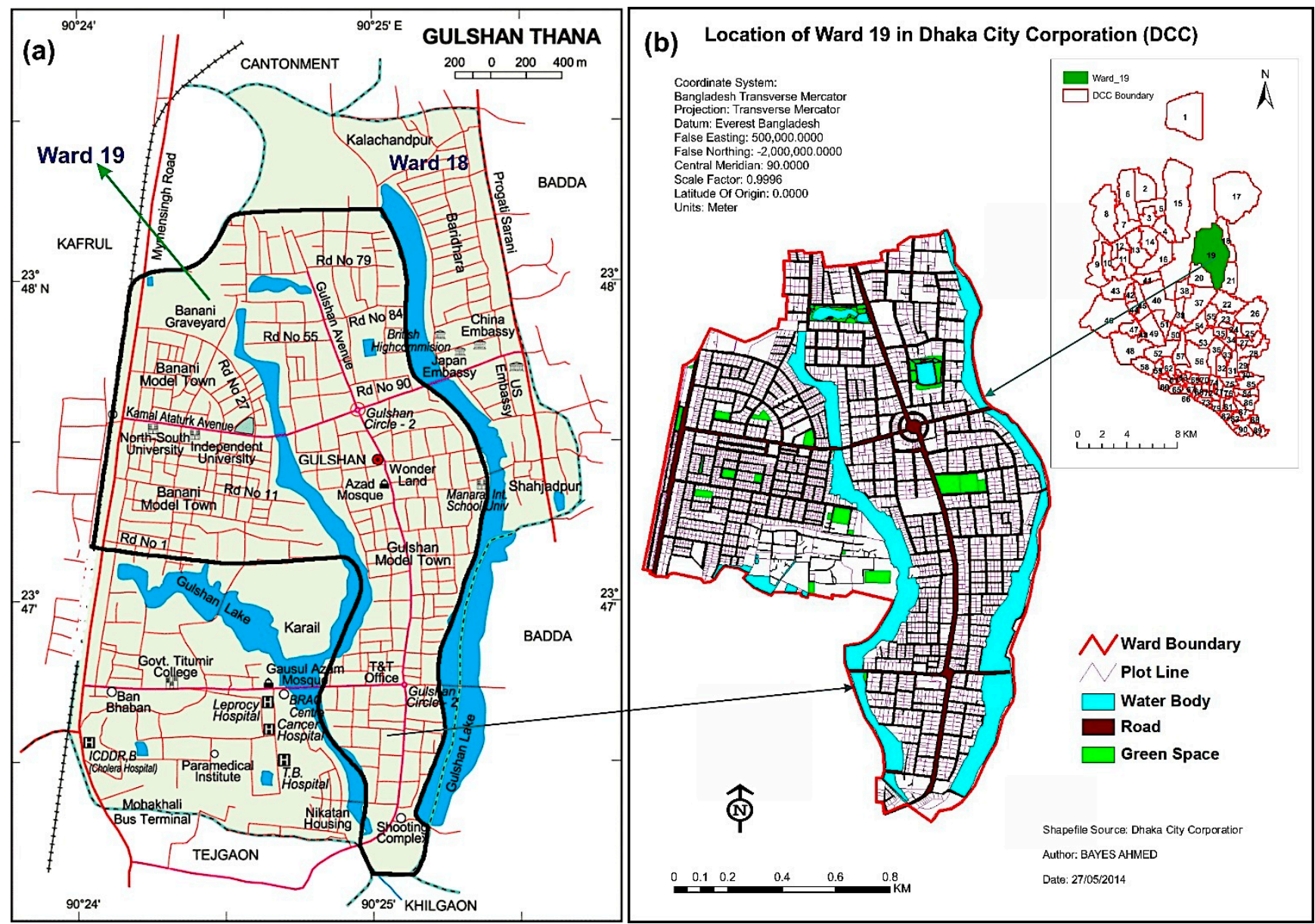

Gulshan was planned as a site and services scheme. It has grid pattern of roads and almost all the plots are rectangular, and of the same size. Three types of roads were designed for the area, viz. major thoroughfares, secondary roads, and access roads [3,10].

\subsubsection{Ward 18: Baridhara, Shahzadpur, and Kalachadpur (Mixed Settlements)}

Ward 18 is also located in Gulshan thana. Ward 18 comprises Baridhara residential area, as well as the Shahzadpur and Kalachadpur areas (Figure 5). Most foreign diplomatic missions in Bangladesh are located in the Gulshan and Baridhara Diplomatic Zones. Baridhara residential area started to develop after the late 1980s. Baridhara is a planned residential area with a grid-iron pattern of road network. The roads are wide and properly laid out as per the norms of formal road hierarchy. On the other hand, Shahzadpur and Kalachadpur areas started to develop from the late 1990s. These are mainly unplanned residential areas. The streets here are narrow and poorly constructed. These areas are growing rapidly by encroaching on the wetlands and water bodies of the eastern part of Dhaka City. 
Figure 5. Location of ward 18 (a) in Gulshan thana and (b) in DCC. Source: (a) Banglapedia, National Encyclopedia of Bangladesh, 2014.

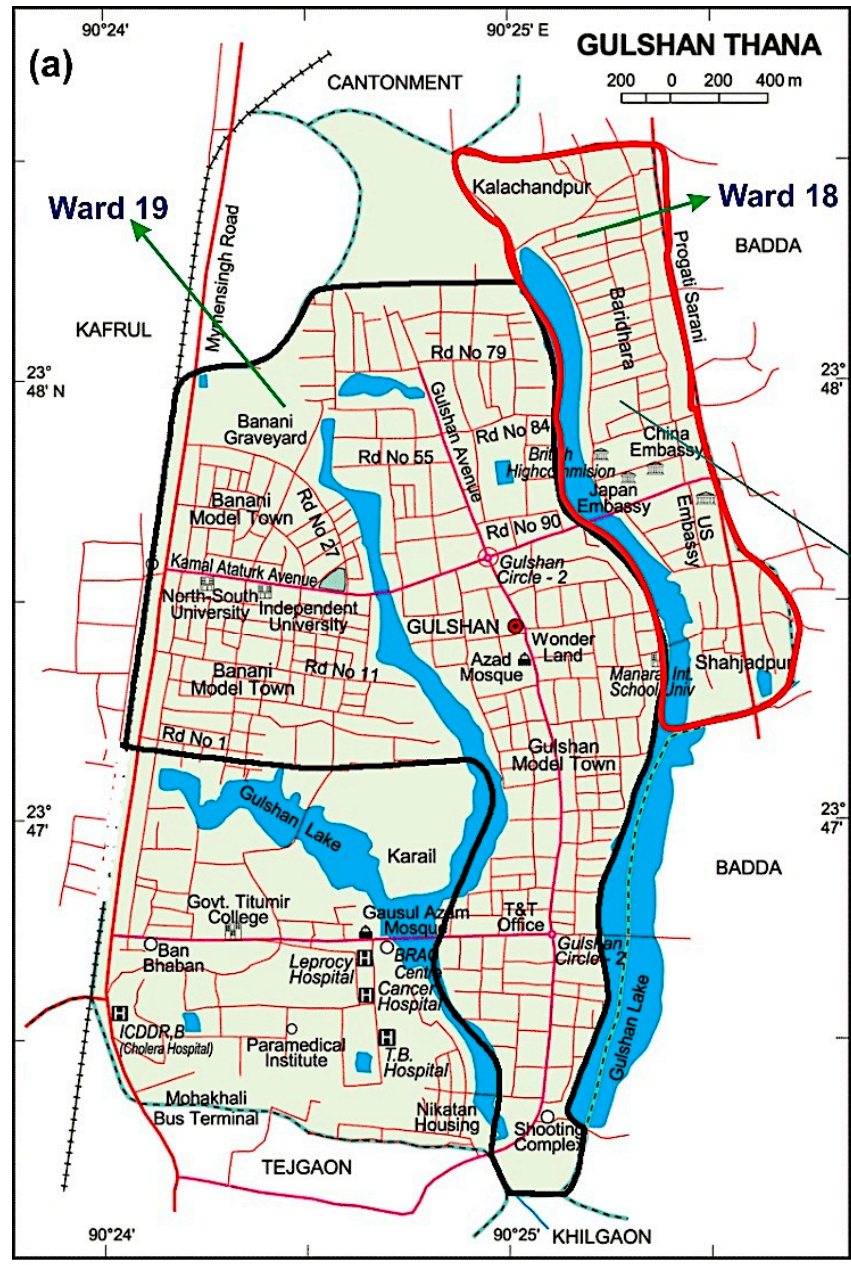

(b) Location of Ward 18 in Dhaka City Corporation (DCC)

Bangladesh Transverse Mercator
Projection: Transverse Mercator Projection: Transverse Mercalor
Datum: Everest Bangladesh False Northing: $-2,000,000,000$ Central Meridian: 90.0000 Scale Factor: 0.9996 Latitude Of Orits: Meter

\section{(1)}
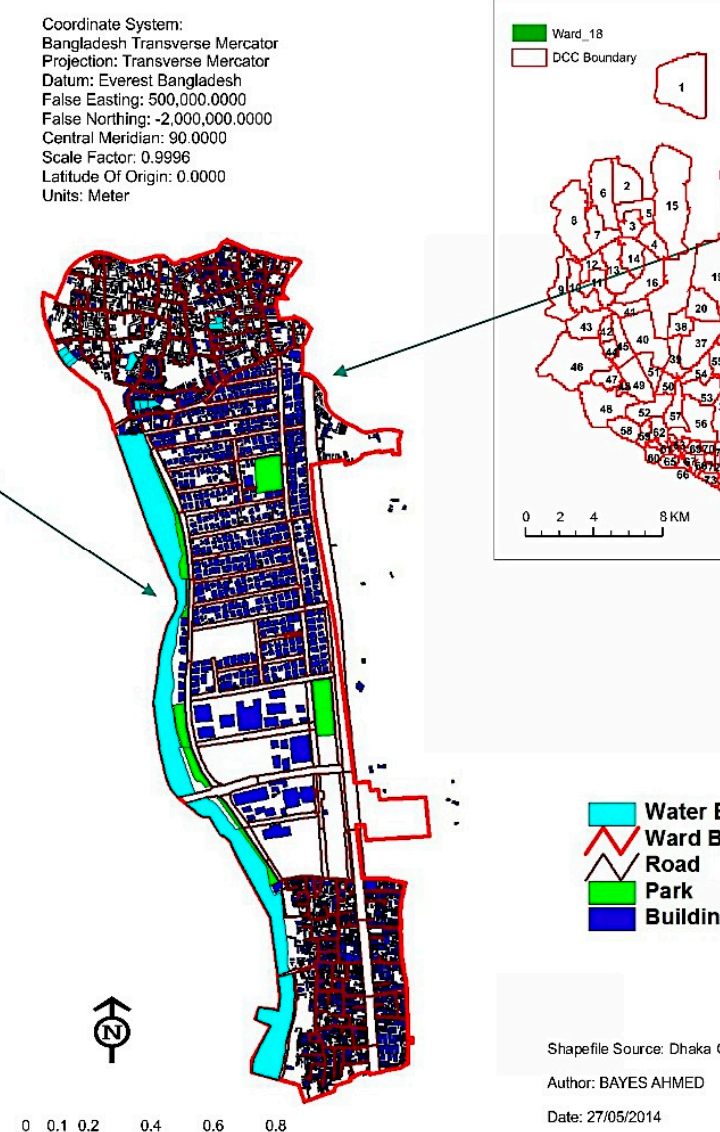

\subsection{Data Collection}

To study the transformation of urban morphology in Dhaka City, secondary data and maps such as Cadastral Survey maps (1912-1914), State Acquisition maps (1958-1962), Revised Survey maps (1965-1985), ward maps, other guide maps, old photographs, and satellite images were collected from different public and private organizations. The base maps of 1952, 1973, 1987, 1995, and 2001 were collected from the Survey of Bangladesh. Moreover, satellite images from the Google Earth (2007) were also used for the morphological analysis. These maps and documents were analyzed to understand the historical growth and change in urban morphology in Dhaka City. The relevant base maps of wards 18,19 , and 72 ; which were used for the syntactic analyses are attached in the Appendix (Figures A2-A4).

\section{Methodology}

The methodological framework of this research concentrates on documenting the evolutionary process through critical reading, interpreting published texts, and analyzing the history. Empirical and syntactic analyses were performed to evaluate the formal aspects of the study areas and trace the 
changes using the collected maps. Analysis of the physical environment and morphological qualities and interpretation of syntactic measures rounded off the study.

\subsection{Theoretical Framework}

Urban morphology is the study of the city as a human habitat. Urban morphologists analyze a city's evolution from its formative years through its subsequent transformations, identifying and dissecting its various components. Special attention is given to how the physical form of a city changes over time and to how different cities compare to each other [11].

The morphological structure in this study is examined through the use of the space syntax method. Space syntax offers a theory and method for investigating society-space relations. The analytical method is based on the transformation of plans into graphs, and quantifying the spatial qualities of nodes using mathematical formulae. Such a method offers a simple, objective procedure for describing, comparing, and interpreting physical forms of human settlements [9].

A number of characteristics make this method a powerful research tool. First, it provides a simple, analyzable, and realistic spatial model of a settlement. Secondly, it entails analysis of the elements of a city as related parts of a system. Thirdly, it gives quantitative values to elements and provides statistical and graphical comparisons within the system. Finally, its computations provide values that allow systems of different sizes to be compared. Apart from the diagrammatic representation of plans, the analytical procedures of space syntax offer a variety of mathematical measurements that quantify various attributes: integration, connectivity, control, and intelligibility values of spatial patterns [9,11]. This is why space syntax is chosen as the tool for the morphological analysis in this study.

For the syntactic analysis, software like "ArcView", with the extension named "Axwoman 3.0" (Axwoman30.avx), and "Microsoft Excel" were used. "Axwoman" is an analytical tool based on space syntax, which runs in Geographic Information System (GIS) environment as "ArcView" extension. Later the axial maps and graphs were analyzed and interpreted. All the relevant images were projected onto the Bangladesh Transverse Mercator (BTM) system using the "Everest Bangladesh" datum.

\subsection{Space Syntax}

Space syntax is the analytical tool used in this study. It is a theory and a set of methods for the analysis of spatial configurations of all kinds. Professor Bill Hillier and his colleagues at Bartlett, University College London originally conceived of space syntax in the 1980s. It is now widely used in a variety of research areas and design applications [12,13]. Using space syntax principles, human displacement patterns in the city can be analyzed, mainly by considering the degree to which urban spaces are integrated and connected. Through the structural analysis of an urban environment, urban planners can derive a better understanding of the evolution of urban areas, and gain better insights to help with the design of new urban layouts [14]. It has been extensively applied in the fields of urban planning, urban design, architecture, transportation planning, and interior design [12,13].

For example, Önder and Gigi (2010) used the space syntax technique for proposing physical and functional recommendations related to the problems identified in the South Haliç Area in Istanbul [15]. Many researchers have used space syntax for analyzing the frequency of pedestrian traffic in the streets [16], to justify the relationship between land use density and urban street configuration [17], 
to interpret the relationship between the urban environment and the traffic network [18], for evaluating reconstruction proposals after road network modeling [19], and to explore the structural pattern of urban road networks [20]. It is evident that the significance of street networks in the urban environment can be analyzed using space syntax. Moreover, in recent years, the space syntax method has been used for planning recreational spaces in urban areas [21], designing new towns [22], to analyze the spatial distribution of urban density [23], to understand the socio-economic conditions of a settlement in terms of overall spatial structure [24], to study the relationship between the built form and economic value [25], and for disaster risk management by analyzing urban patterns [26].

In the space syntax method, the analysis of an urban grid is based on the axial map. An axial map records the least set of longest and straightest lines of sight and access that covers the public system of open spaces of the city and connects all the street intersections present in the urban grid [3]. An axial map is basically different from a street map. It expresses the importance of sight, and accordingly the representation may join two roads along the same axis into one and break one curvilinear road into a number of connected lines. These axial maps are used in the space syntax method as the basis for deriving a series of measures of the properties of the configuration of the street grid [13].

The most important measure is integration, which is the relative depth or shallowness of any spatial system seen from any particular point within it. Integration is a global static measure where every axial line is assigned a value that characterizes its relation to all other lines in the grid, thus providing a global index of relative integration or segregation for that line relative to all others $(\mathrm{R}=n)$ [3]. Therefore, integration of a line is by definition a value that indicates the degree to which the line is more integrated, or segregated/inaccessible, from a system as a whole. The measure is actually based on a more basic notion called depth [13]. Depth is more generally a topological distance in a graph. If two lines are directly connected, then the distance between them is equal to one, and the distance of a pair of lines that are not directly connected is the shortest path between them [27].

Integration is a global measure, as the calculation of integration is based on the total depth from the current. However, if a number of depths, instead of all depths, are considered, then the integration is called local integration [13]. The numerical value ranges from higher than 0 to 1 , and within this range; higher values indicate low integration and vice versa [9]. The depth $(D)$ is given by Equation (1):

$$
D=\frac{2(M D-1)}{K-2}
$$

where $M D$ is tile mean depth or the mean number of spaces away from all the other spaces in the system from the selected space, and $K$ is the total number of spaces in the system. A correcting factor is applied to eliminate the empirical effects of size [13].

The integration values are then rank ordered from the most integrated to the most segregated line, divided into five integration bands, and each band is assigned with a grey scale tone to represent its degree of integration, with black representing the most integrated band and the palest grey the most segregated. These tones are then transferred to the axial map as a distribution of integration, which will show in black, the set of the most integrated streets which draw the urban grid together, and which are collectively known as an integration core [3]. The integration core of an area most of the time coincides with the functional core of the city. 
However, depending on the size and segments of the axial map, the urban core is formed with $1 \%$ to $10 \%$ of highest integrated lines of the urban grid. Global integration considers the total city structure as a whole, while local integration only characterizes the pattern of locality-based integration at a small scale [27].

The second measure is choice $(\mathrm{CH})$, which expresses the extent to which a particular space (axial line) figures as a choice on all shortest routes from all spaces to all other spaces in the system. The higher choice lines influence global relations of through movement, thus it is considered to be a global dynamic measure $[9,13]$.

There are parallel local measures as well. Connectivity $(\mathrm{CN})$ is literally the number of axial lines that connect to, or intersect with, each line in the system. It is a local static measure. On the other hand, the measure of local control $(\mathrm{CV})$ represents the amount of choice of a space, which represents its immediate neighbors as somewhere to go. Thus it gives rise to a local dynamic measure. High values of control indicate better connection of a space in comparison with its neighbors $[9,13]$.

In addition to these four first-order syntactic measures, a second-order measure, intelligibility, is also applied. It is the correlation between the local and the global properties of spaces, which expresses the degree to which the local properties of space are a good guide to their properties in terms of the system as a whole $[9,13]$. The stronger the correlation, the more we can infer the global position of a space from its directly observable local connections [28,29].

The second-order measures even have sociological potential, such as the correlation between integration $(\mathrm{R}=n)$ and connectivity $(\mathrm{CN})$ expressing the extent to which the axial information is available to an individual moving through a particular space about how it relates to its neighbors locally, and also gives reliable information about the large scale global structure of the grid $[3,9,13]$.

\section{Findings}

Dhaka has grown in size, scale, and extent as the urban function of this city evolved and changed according to its political and commercial status. In this research, the configurational analysis in terms of space syntax is performed to identify the global-local integration, connectivity, and the spatial relationship between different syntactic measures in relation to the changing pattern of urban settlement patters. Moreover, through the morphological analysis, the development pattern of urban spaces as well as the importance of street network, both locally and globally, is identified.

The analysis is done for the period since the end of British colonial rule in 1947. The selection of the timeframe was based on the facts that this was the period of Dhaka's most rapid growth and more detailed maps of Dhaka City were available for this period. The morphological analysis is carried out at six different stages $(1952,1973,1987,1995,2001$, and 2007) for wards 18, 19, and 72.

The selection of the time periods was based on the availability of detailed guide maps of Dhaka City. As Gulshan model town started developing from the early 1960s, the map of 1952 was not considered for syntactic analysis of ward 19. Baridhara Model Town, Shahzadpur and Kalachadpur make up ward 18. RAJUK started developing Baridhara as a planned residential area from 1990. Therefore, it was not possible to draw the axial maps of ward 18 for 1973 and 1987. Therefore, only three post-1990 base maps $(1995,2001$, and 2007) were considered for ward 18. 


\subsection{Generating the Syntactic Measures}

\subsubsection{Global Integration Core}

The integration core of a city is mainly formed with the highest integrated axial lines. The integration core is generally concentrated in the heart of the commercial and ceremonial center [3]. The axial maps of different periods were used for syntactic analysis, where the highest and lowest range of global integration values $(\mathrm{R}=n)$ is shown in five different bands of gray color (Figures 6-8).

Figure 6. Global integration $(\mathrm{R}=n)$ maps of (Old Dhaka) ward 72 (not to scale).
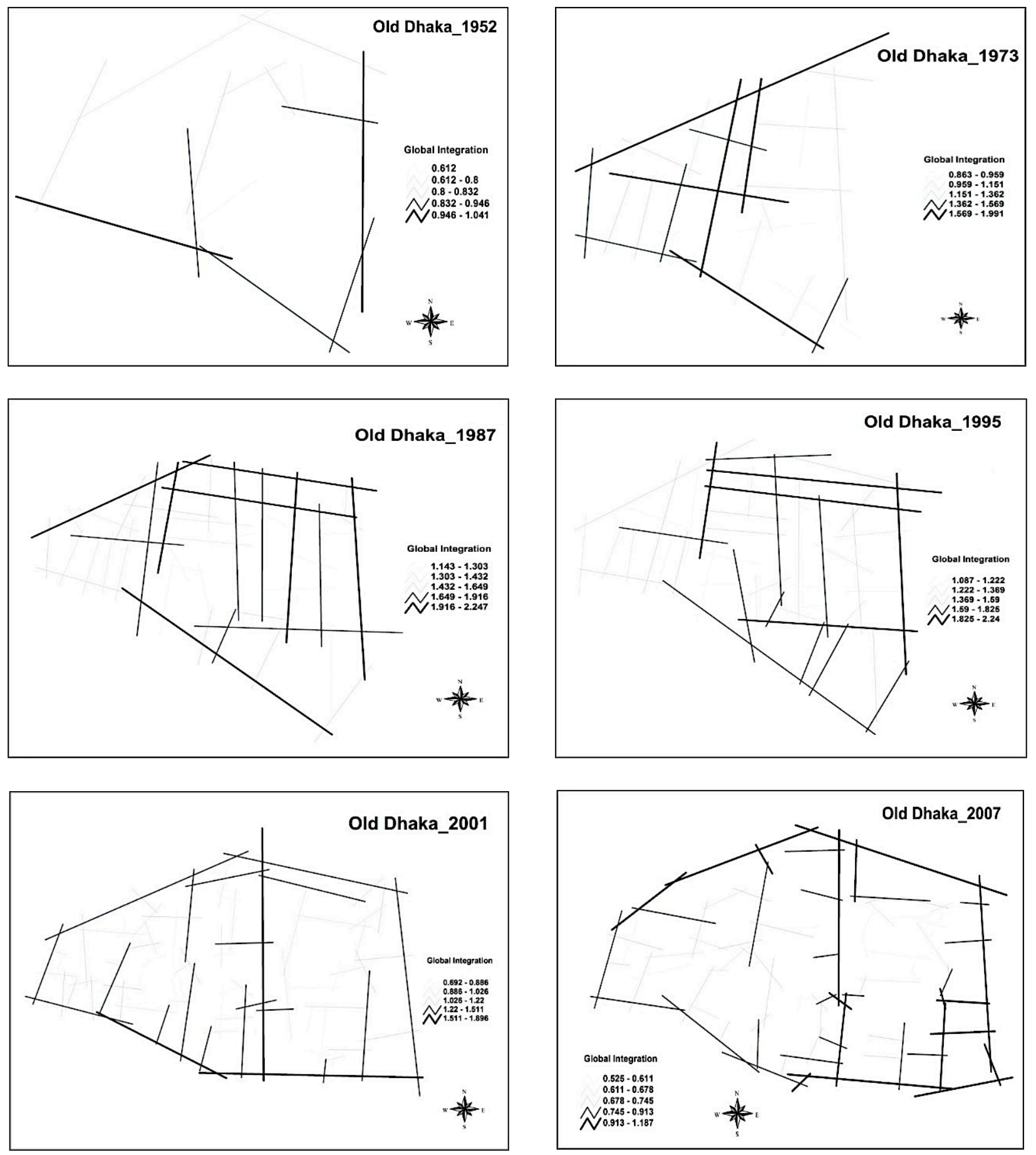
Figure 7. Global integration $(\mathrm{R}=n)$ maps of ward 19 (Gulshan) in different time periods (not to scale).
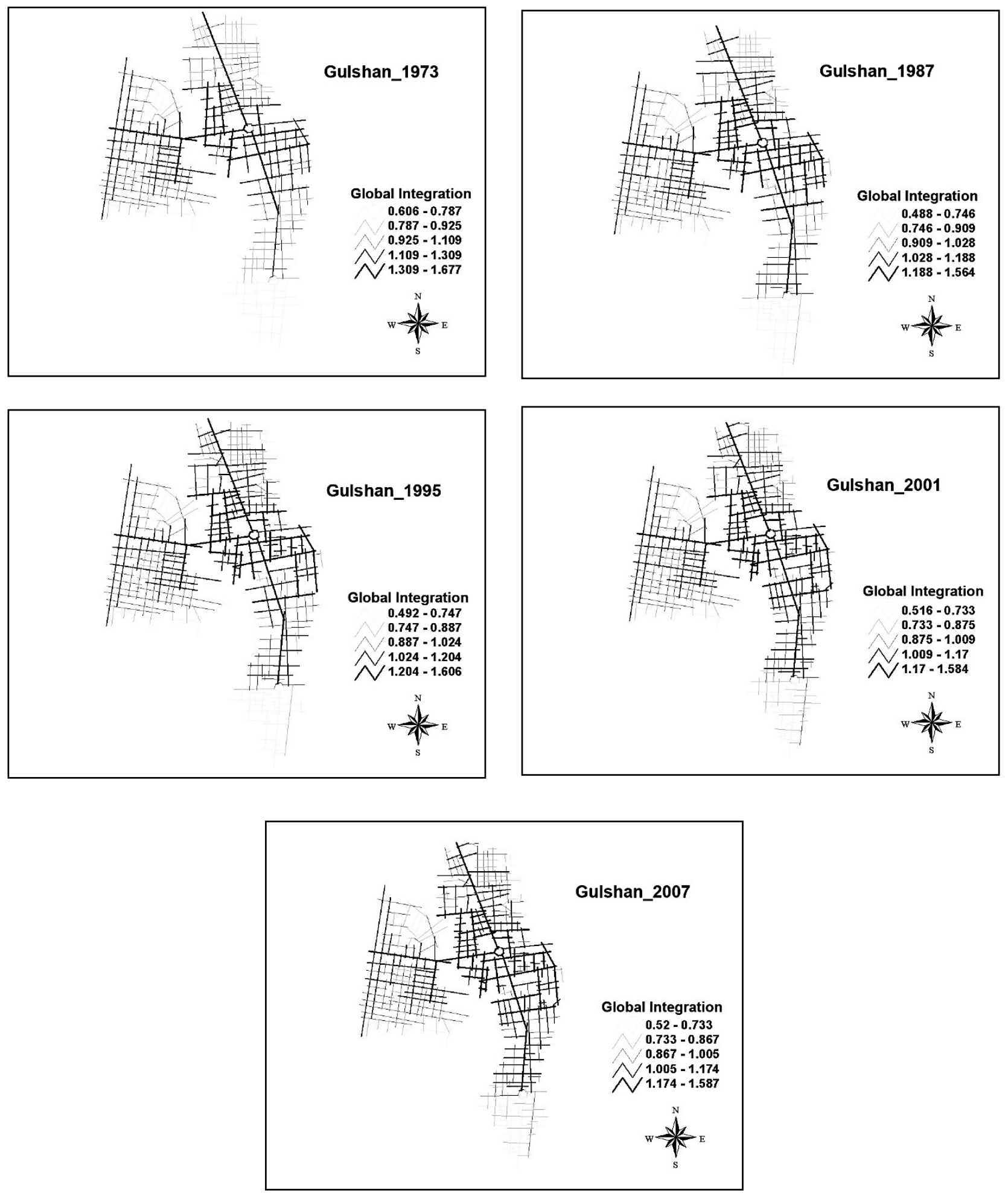

4.1.2. Connectivity and Control

Connectivity $(\mathrm{CN})$ of a space literally means how many spaces intersect with it. Control Value (CV) is a dynamic local measure. It measures the degree to which a space controls access to its immediate 
neighbors by taking into account the number of alternative connections that each of these neighbors has $[3,9]$. The connectivity maps of the wards are shown in Figures 9-11.

Figure 8. Global integration $(\mathrm{R}=n)$ maps of ward 18 (Baridhara) in different time periods (not to scale).
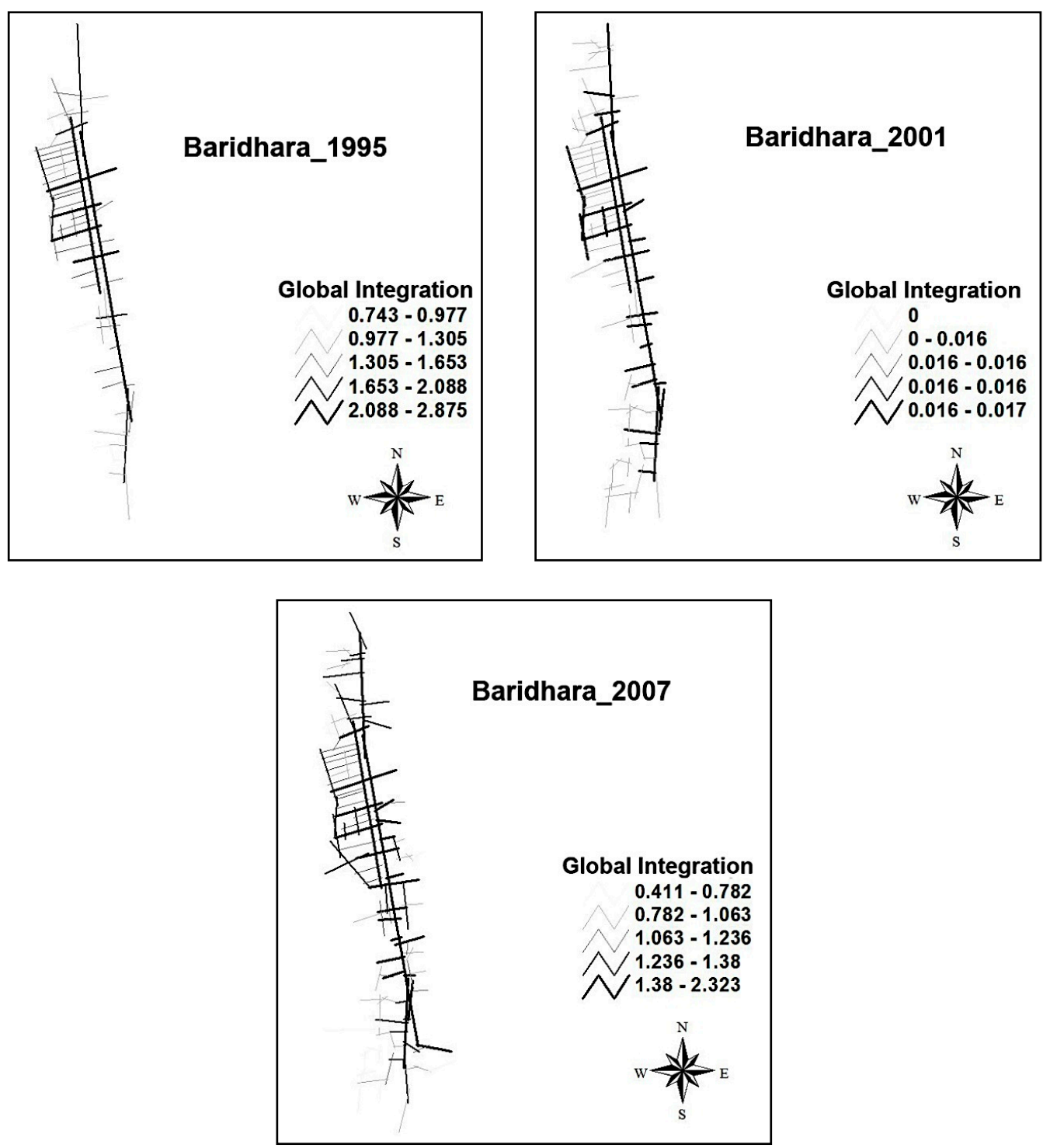

\subsubsection{Global $(\mathrm{R}=n)$ and Local $(\mathrm{R}=3)$ Integration Pattern}

It has already been mentioned that integration in general is a depth measure of different spatial systems. The mean global integration $(\mathrm{R}=n)$ of a system gives an indication of the amount of hierarchy present in the system as a whole, in the sense of representing average directness or indirectness of connections between spaces. Global integration represents the hierarchical variation of integration within the total city structure, whereas local integration signifies the local importance of the road network $[3,9]$. The global and local integration values are shown in Tables 1-3. 
Figure 9. Connectivity maps of ward 72 (Old Dhaka) in different time periods (not to scale).
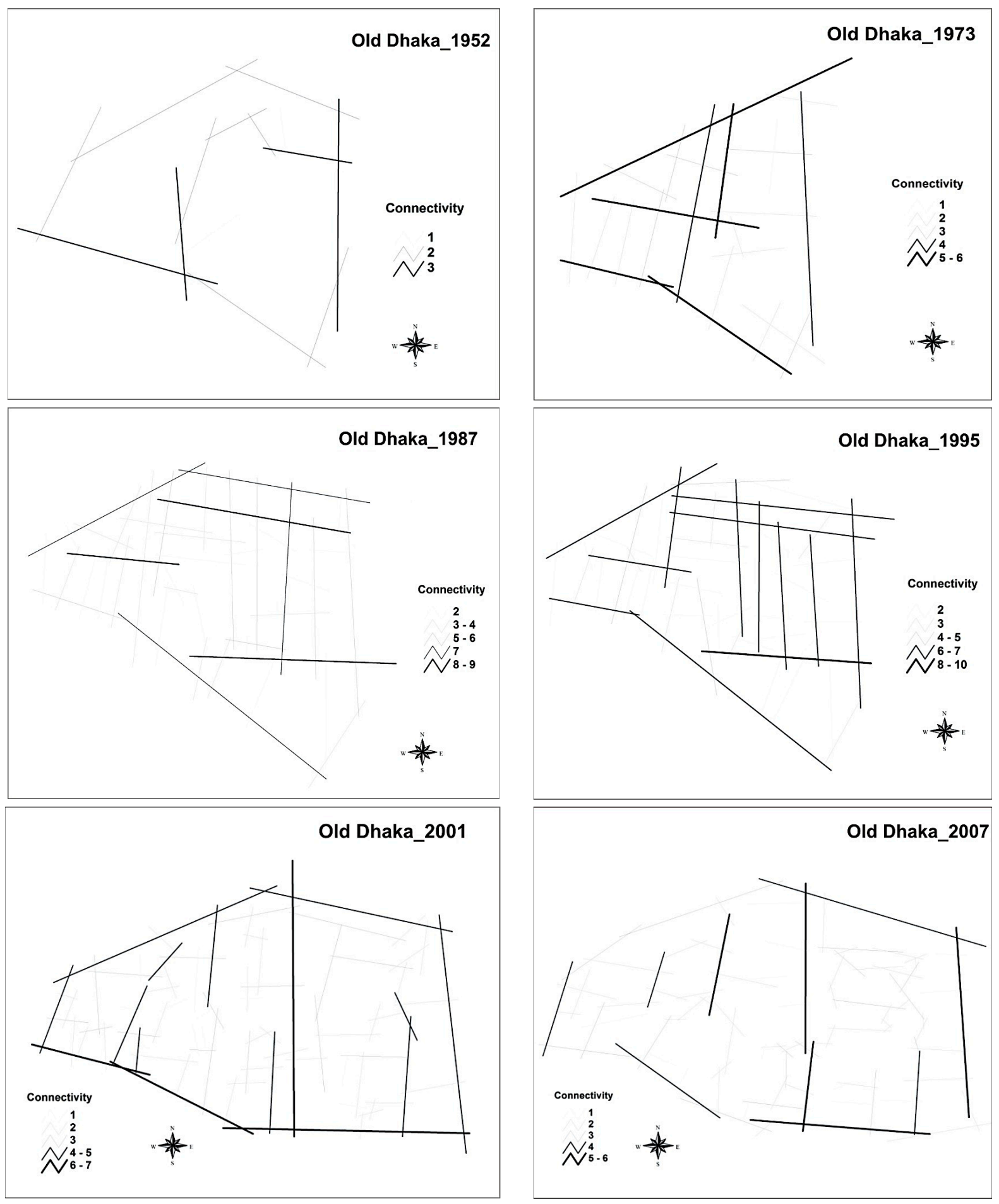

\subsubsection{Intelligibility}

According to the space syntax theory, the local and global characteristics of urban systems are not the only important issues; the interaction between them and the correspondence between the local and global configurations of space are significant as well $[3,9]$. 
Figure 10. Connectivity maps of ward 19 (Gulshan) in different time periods (not to scale).

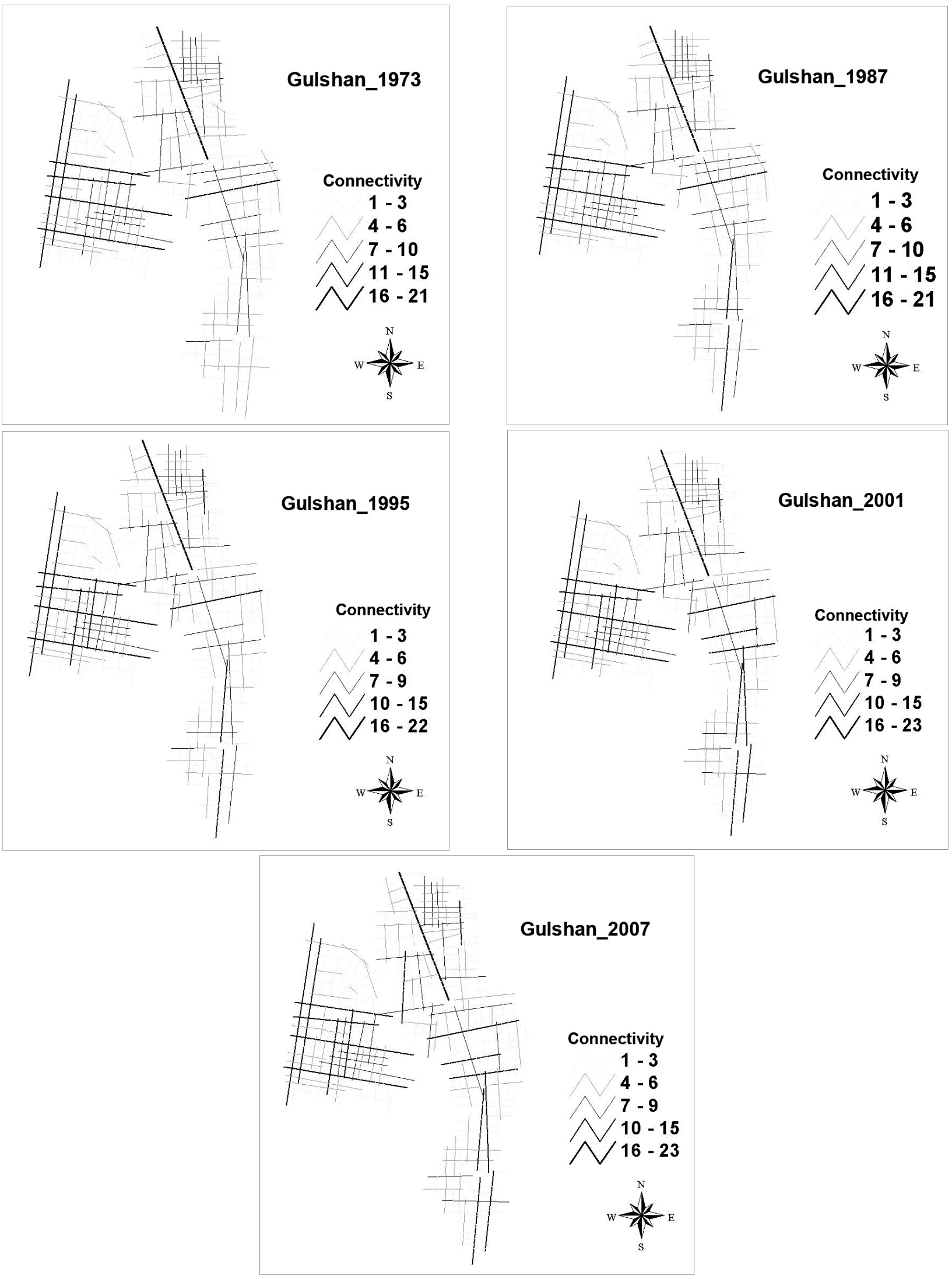


Figure 11. Connectivity maps of ward 18 (Baridhara) in different time periods (not to scale).
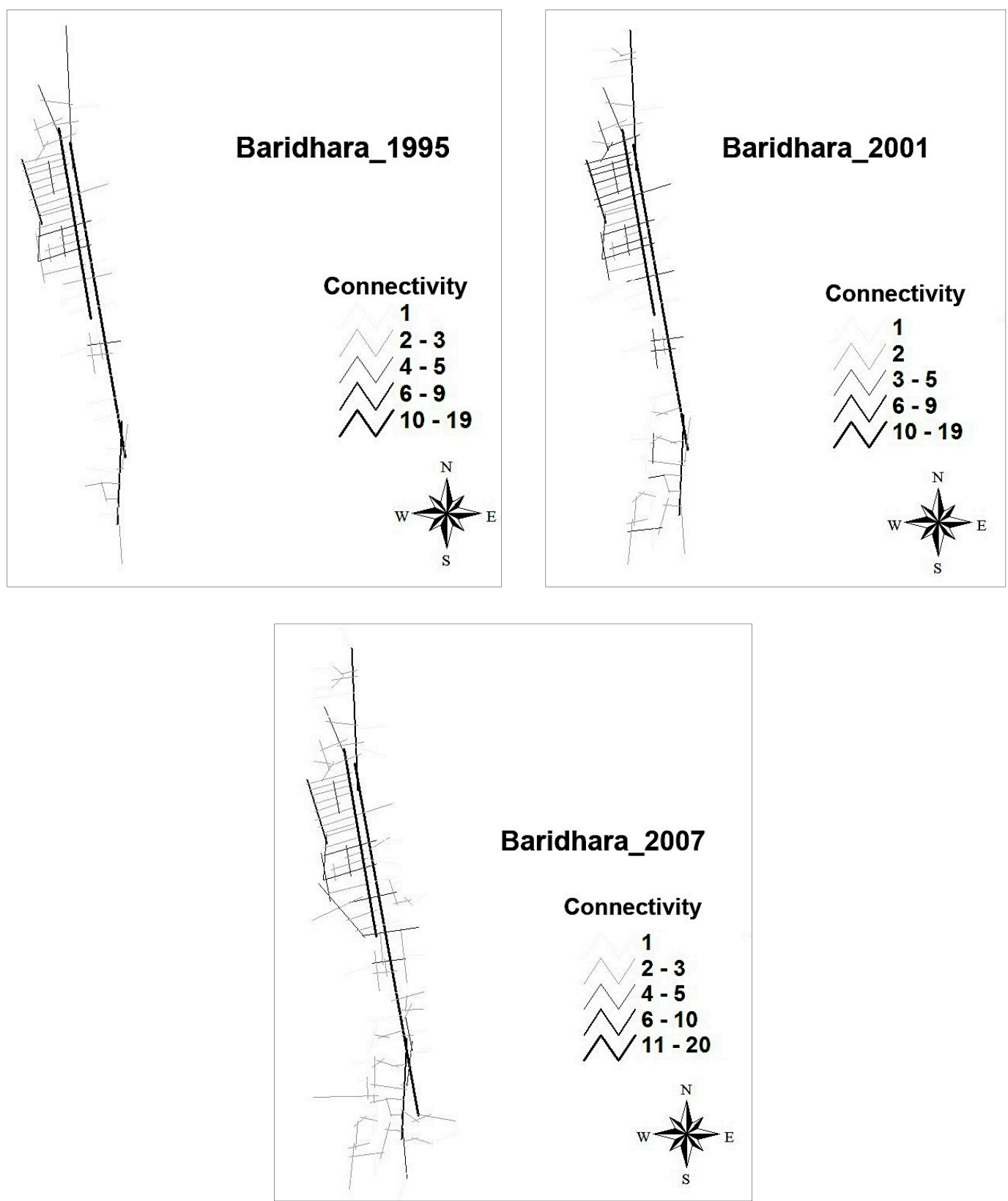

The intelligibility of an urban system is the degree of correlation between the global and local properties of each line in the system. The correlation value of syntactic measures epitomizes the local and global relationship as well as the importance of any urban grid structure as a "part-whole" system.

A globally important road may not create impact on a local grid network; on the other hand, a locally important road can be isolated and disintegrated from the urban core of the city. More precisely, the correlation value as well as the slope of the scattergram can describe this part-whole relationship in the urban grid. The scattergram is used as a tool to explore the correlation between the local and global measures of a city $[9,27]$.

If the average correlation value is close to 0.5 , it produces a tight and linear scattergram with comparatively greater slope. Linearity in scatters implies a good relationship between the local and global measures; a steeper slope of the regression line entails a higher degree of integration [3,9,27]. 
After summarizing the correlation values of the local and global measures (Tables 4-6), the relationships between global integration on the one hand and local integration and connectivity on the other are compared. The scattergrams of correlation between the global and local measures, both $(\mathrm{R} n-\mathrm{R} 3)$ and $(\mathrm{R} n-\mathrm{CN})$, are shown in Figures 12-14.

\subsection{Analyses of the Syntactic Measures}

\subsubsection{Summary of the Syntactic Analysis of Ward 72}

(a) The integration core lies generally along Shakhari Bazar Road, English Road, Johnson Road, and Kotwali Road (Figure 6). These roads are the important administrative and commercial hubs of this area.

(b) The number of segments in the core is increasing throughout the years (Table 1). It means that the road network is expanding.

(c) Shakhari Bazar and Kotwali roads show the highest connectivity and control values over the years (Figure 9).

(d) The global and local integration remain almost constant and balanced in all phases (Table 1). This indicates that the locally important roads are always important for the local inhabitants irrespective of the global measures.

(e) It also suggests that the changes in the urban grid in recent times were particularly detrimental. Actually, throughout the years, the population density and building height of this area was increasing without recourse to any formal planning. This has led to locally important roads being isolated and disintegrated from the urban core.

Table 1. Syntactic measures of ward 72 (Old Dhaka) in different time periods.

\begin{tabular}{cccccccc}
\hline Syntactic Measures & Time Period & $\mathbf{1 9 5 2}$ & $\mathbf{1 9 7 3}$ & $\mathbf{1 9 8 7}$ & $\mathbf{1 9 9 5}$ & $\mathbf{2 0 0 1}$ & $\mathbf{2 0 0 7}$ \\
\hline & Segment No. & 14 & 24 & 44 & 48 & 79 & 87 \\
Integration Global & $\mathrm{R}=n$ Max & 1.0405 & 1.9912 & 2.2465 & 2.2398 & 1.8958 & 1.1870 \\
$\mathbf{R}=\boldsymbol{n}$ & $\mathrm{R}=n$ Min & 0.6120 & 0.8628 & 1.1430 & 1.0869 & 0.6921 & 0.5247 \\
& $\mathrm{R}=n$ Mean & 0.8585 & 1 & 1.5620 & 1 & 1.0818 & 0.7671 \\
& Std. Deviation & 0.1323 & 0.3227 & 0.2674 & 0.2865 & 0.2472 & 0.1510 \\
\hline \multirow{4}{*}{ Integration Local } & $\mathrm{R}=3$ Max & 1.7239 & 2.9422 & 3.6980 & 3.8832 & 3.2143 & 3.0309 \\
$\mathbf{R = 3}$ & $\mathrm{R}=3$ Min & 0.5000 & 0.5000 & 1.2737 & 1.1634 & 0.2109 & 0.2109 \\
& $\mathrm{R}=3$ Mean & 1.2098 & 1.8533 & 2 & 2.2081 & 1.5369 & 1.4014 \\
& Std. Deviation & 0.3994 & 0.6220 & 0.6624 & 0.6752 & 1 & 0.5725 \\
\hline Connectivity & CN Max & 3 & 6 & 9 & 10 & 7 & 6 \\
$(\mathbf{C N})$ & CN Min & 1 & 1 & 2 & 2 & 1 & 1 \\
& CN Mean & 2 & 3 & 4 & 3.6250 & 2.6075 & 2.3448 \\
& Std. Deviation & 0.6629 & 1.4116 & 2.1085 & 2.1499 & 1.2951 & 1.0764 \\
\hline Control & CV Max & 1.8333 & 2.2833 & 2.8333 & 3.5595 & 2.3666 & 3.7500 \\
$(\mathbf{C V})$ & CV Min & 0.3333 & 0.3333 & 0.2539 & 0.2428 & 0.2500 & 0.1666 \\
& CV Mean & 1 & 1 & 1 & 1 & 1 & 1 \\
& Std. Deviation & 0.4529 & 0.6005 & 1 & 0.8586 & 0.5288 & 0.6603 \\
\hline
\end{tabular}


(f) The local global connectivity $(\mathrm{R} n-\mathrm{CN})$ is found comparatively low, which suggests the lower connected linearity of this area. However, the local global integration (Rn-R3) is moderately high, which reveals both the global and local importance of ward 72 (Table 4 and Figure 12).

Table 2. Syntactic measures of ward 19 (Gulshan) in different time periods.

\begin{tabular}{ccccccc}
\hline Syntactic Measures & Time Period & $\mathbf{1 9 7 3}$ & $\mathbf{1 9 8 7}$ & $\mathbf{1 9 9 5}$ & $\mathbf{2 0 0 1}$ & $\mathbf{2 0 0 7}$ \\
\hline & Segment No. & 217 & 246 & 280 & 307 & 316 \\
Integration Global & $\mathrm{R}=n$ Max & 1.67741 & 1.56433 & 1.60611 & 1.58368 & 1.58726 \\
$\mathbf{R}=\boldsymbol{n}$ & $\mathrm{R}=n$ Min & 0.60603 & 0.48831 & 0.49204 & 0.51589 & 0.52042 \\
& $\mathrm{R}=n$ Mean & 1.01691 & 0.97269 & 0.98003 & 0.96249 & 0.96299 \\
& Std. Deviation & 0.203706 & 0.197051 & 0.201944 & 0.195078 & 0.195516 \\
\hline \multirow{5}{*}{ Integration Local } & $\mathrm{R}=3$ Max & 5.52801 & 5.46918 & 5.58466 & 5.69637 & 5.69637 \\
$\mathbf{R}=\mathbf{3}$ & $\mathrm{R}=3$ Min & 0.21093 & 0.21093 & 0.21093 & 0.21093 & 0.21093 \\
& $\mathrm{R}=3$ Mean & 2.34078 & 2.27591 & 2.16151 & 2.15832 & 2.13796 \\
& Std. Deviation & 0.832402 & 0.880432 & 0.934867 & 0.954401 & 0.962622 \\
\hline \multirow{4}{*}{ Connectivity } & CN Max & 21 & 21 & 22 & 23 & 23 \\
$(\mathbf{C N})$ & CN Min & 1 & 1 & 1 & 1 & 1 \\
& CN Mean & 4.15668 & 4 & 3.77857 & 3.70033 & 3.65823 \\
& Std. Deviation & 2.762742 & 2.812509 & 2.814626 & 2.901673 & 2.897776 \\
\hline Control & CV Max & 5.81071 & 5.83333 & 6.05238 & 8.30952 & 8.30952 \\
$(\mathbf{C V})$ & CV Min & 0.12500 & 0.08333 & 0.09091 & 0.07143 & 0.07143 \\
& CV Mean & 1 & 1 & 1 & 1 & 1 \\
& Std. Deviation & 0.748989 & 0.824897 & 0.82999 & 0.941863 & 0.957755 \\
\hline
\end{tabular}

Table 3. Syntactic measures of ward 18 (Baridhara) in different time periods.

\begin{tabular}{ccccc}
\hline Syntactic Measures & Time Period & $\mathbf{1 9 9 5}$ & $\mathbf{2 0 0 1}$ & $\mathbf{2 0 0 7}$ \\
\hline & Segment No. & 59 & 64 & 116 \\
Integration Global & $\mathrm{R}=n$ Max & 2.87544 & 3.13252 & 2.32346 \\
$\mathbf{R}=\boldsymbol{n}$ & $\mathrm{R}=n$ Min & 0.74309 & 0.90779 & 0.41149 \\
& $\mathrm{R}=n$ Mean & 1.50835 & 1.59059 & 1.18374 \\
& Std. Deviation & 0.40984 & 0.42213 & 0.33398 \\
\hline & $\mathrm{R}=3$ Max & 6.75685 & 6.19064 & 6.06299 \\
Integration Local & $\mathrm{R}=3$ Min & 0.50003 & 0.21093 & 0.21093 \\
$\mathbf{R}=\mathbf{3}$ & $\mathrm{R}=3$ Mean & 2.18363 & 2.16773 & 1.79783 \\
& Std. Deviation & 1.03783 & 1.04257 & 1.03977 \\
\hline & CN Max & 19 & 19 & 20 \\
Connectivity & CN Min & 1 & 1 & 1 \\
$(\mathbf{C N})$ & CN Mean & 3.01695 & 2.96875 & 2.70690 \\
& Std. Deviation & 3.15404 & 3.27069 & 2.75686 \\
\hline & CV Max & 9.70952 & 11.49167 & 9.74167 \\
Control & CV Min & 0.05263 & 0.05556 & 0.05000 \\
$(\mathbf{C V})$ & CV Mean & 1.00000 & 1.00000 & 1.00000 \\
& Std. Deviation & 1.72539 & 1.82773 & 1.30540 \\
\hline
\end{tabular}


Table 4. Correlation values of global and local measures of ward 72 (where $\mathrm{R}=$ correlation, $\mathrm{R} n=$ global integration, $\mathrm{R} 3=$ local integration, and $R^{2}=$ tangent of slope).

\begin{tabular}{ccccc}
\hline Time Period & $\begin{array}{c}\text { R of } \\
\text { Rn-R3/ } \\
\text { Intelligibility }\end{array}$ & Equation & $\begin{array}{c}\text { R of } \\
\text { Rn-CN/ } \\
\text { Intelligibility }\end{array}$ & Equation \\
\hline $\mathbf{1 9 5 2}$ & 0.926891 & $\mathrm{y}=2.7967 \mathrm{x}-1.1913$ & 0.904338 & $\mathrm{y}=4.5295 \mathrm{x}-1.746$ \\
& & $R^{2}=0.8591$ & $R^{2}=0.8178$ \\
$\mathbf{1 9 7 3}$ & 0.933863 & $\mathrm{y}=1.7996 \mathrm{x}-0.6459$ & 0.857795 & $\mathrm{y}=3.7514 \mathrm{x}-2.1265$ \\
& & $R^{2}=0.8721$ & $R^{2}=0.7358$ \\
$\mathbf{1 9 8 7}$ & 0.909904 & $\mathrm{y}=2.0102 \mathrm{x}-0.8549$ & 0.853305 & $\mathrm{y}=6.0005 \mathrm{x}-5.5092$ \\
& & $R^{2}=0.8279$ & $R^{2}=0.7281$ \\
$\mathbf{1 9 9 5}$ & 0.837952 & $\mathrm{y}=1.9749 \mathrm{x}-0.7281$ & 0.764556 & $\mathrm{y}=5.7367 \mathrm{x}-4.9044$ \\
& & $R^{2}=0.7022$ & & $R^{2}=0.5845$ \\
$\mathbf{2 0 0 1}$ & 0.870061 & $\mathrm{y}=2.3976 \mathrm{x}-1.057$ & 0.813903 & $\mathrm{y}=4.2633 \mathrm{x}-2.0048$ \\
& & $R^{2}=0.757$ & & $R^{2}=0.6624$ \\
$\mathbf{2 0 0 7}$ & 0.628307 & $\mathrm{y}=2.3819 \mathrm{x}-0.4258$ & 0.493269 & $\mathrm{y}=3.5161 \mathrm{x}-0.3525$ \\
& & $R^{2}=0.3948$ & & $R^{2}=0.2433$ \\
\hline
\end{tabular}

Table 5. Correlation values of global and local measures of ward 19 (where $\mathrm{R}=$ correlation, $\mathrm{R} n=$ global integration, $\mathrm{R} 3=$ local integration, and $R^{2}=$ tangent of slope).

\begin{tabular}{ccccc}
\hline Time Period & $\begin{array}{c}\mathbf{R} \text { of } \\
\mathbf{R} \boldsymbol{n} \text {-R3/ } \\
\text { Intelligibility }\end{array}$ & Equation & $\begin{array}{c}\text { R of } \\
\text { Rn-CN/ } \\
\text { Intelligibility }\end{array}$ & Equation \\
\hline $\mathbf{1 9 7 3}$ & 0.6324 & $\mathrm{y}=3.2528 \mathrm{x}-1.1008$ & 0.5145 & $\mathrm{y}=6.9476 \mathrm{x}-3.2858$ \\
& & $R^{2}=0.3999$ & $R^{2}=0.2647$ \\
$\mathbf{1 9 8 7}$ & 0.6448 & $\mathrm{y}=3.2697 \mathrm{x}-1.1436$ & 0.5127 & $\mathrm{y}=7.0548 \mathrm{x}-3.4505$ \\
& & $R^{2}=0.4158$ & $R^{2}=0.2629$ \\
$\mathbf{1 9 9 5}$ & 0.6415 & $\mathrm{y}=3.3334 \mathrm{x}-1.1803$ & 0.5087 & $\mathrm{y}=7.4398 \mathrm{x}-3.7375$ \\
& & $R^{2}=0.4115$ & $R^{2}=0.2588$ \\
$\mathbf{2 0 0 1}$ & 0.6210 & $\mathrm{y}=3.1117 \mathrm{x}-0.8111$ & 0.4766 & $\mathrm{y}=6.7344 \mathrm{x}-2.6907$ \\
& & $R^{2}=0.3856$ & & $R^{2}=0.2271$ \\
$\mathbf{2 0 0 7}$ & 0.5931 & $\mathrm{y}=3.0133 \mathrm{x}-0.6883$ & 0.4494 & $\mathrm{y}=6.5249 \mathrm{x}-2.4231$ \\
& & $R^{2}=0.3518$ & $R^{2}=0.2020$ \\
\hline
\end{tabular}

\subsubsection{Summary of Syntactic Analysis of Ward 19}

In all the phases, the integration core remained almost unchanged for ward 19 (Figure 2). The core follows Gulshan Avenue, Kamal Ataturk Avenue, Madani Avenue, and a few other roads (Roads 33, 35, 48, 54, 55, 64, 70, 90, 99, 103, 104, and 113 of Gulshan-2; and Roads 8, and 10 of Banani) from Gulshan to Baridhara and Banani Model Towns (Figures 4 and 7). The segment numbers are almost 
unchanged (Table 2). This is because of the planned and grid-iron type road network in Gulshan. There is a slight increase found in the segment numbers in later decades (Table 2). This is observed because of the development of some unplanned residential areas in the northeastern parts (Figures 4 and 7).

Table 6. Correlation values of global and local measures of ward 18 (where $\mathrm{R}=$ correlation, $\mathrm{R} n=$ global integration, $\mathrm{R} 3=$ local integration, and $R^{2}=$ tangent of slope).

\begin{tabular}{ccccc}
\hline Time Period & $\begin{array}{c}\mathbf{R} \text { of } \\
\mathbf{R} \boldsymbol{n} \text {-R3/ } \\
\text { Intelligibility }\end{array}$ & Equation & $\begin{array}{c}\mathbf{R} \text { of } \\
\mathbf{R} \boldsymbol{n} \text {-CN/ } \\
\text { Intelligibility }\end{array}$ & Equation \\
\hline $\mathbf{1 9 9 5}$ & 0.7760 & $\mathrm{y}=1.9649 \mathrm{x}-0.7802$ & 0.6082 & $\mathrm{y}=4.6805 \mathrm{x}-4.0429$ \\
& & $R^{2}=0.6021$ & & $R^{2}=0.3699$ \\
$\mathbf{2 0 0 1}$ & 0.8041 & $\mathrm{y}=1.9858 \mathrm{x}-0.9909$ & 0.6478 & $\mathrm{y}=5.0191 \mathrm{x}-5.0146$ \\
& & $R^{2}=0.6465$ & & $R^{2}=0.4196$ \\
$\mathbf{2 0 0 7}$ & 0.7867 & $\mathrm{y}=2.45 \mathrm{x}-1.1023$ & 0.5090 & $\mathrm{y}=4.2015 \mathrm{x}-2.2666$ \\
& & $R^{2}=0.6193$ & & $R^{2}=0.2591$ \\
\hline
\end{tabular}

The most connected road (Figure 10) in all the phases is the one from Gulshan-2 circle towards the Cantonment (part of Gulshan Avenue). Global roads have higher connectivity and control values than local ones (Figure 10 and Table 2). Global roads are found more integrated and accessible, while local roads are much more segregated and inaccessible (Table 5). It proves that the locally important roads are less important to the local inhabitants, irrespective of the global measures in ward 19.

Figure 12. Scatter of correlation between local and global measures (Rn-R3) and (Rn-CN) of ward 72 (Old Dhaka).
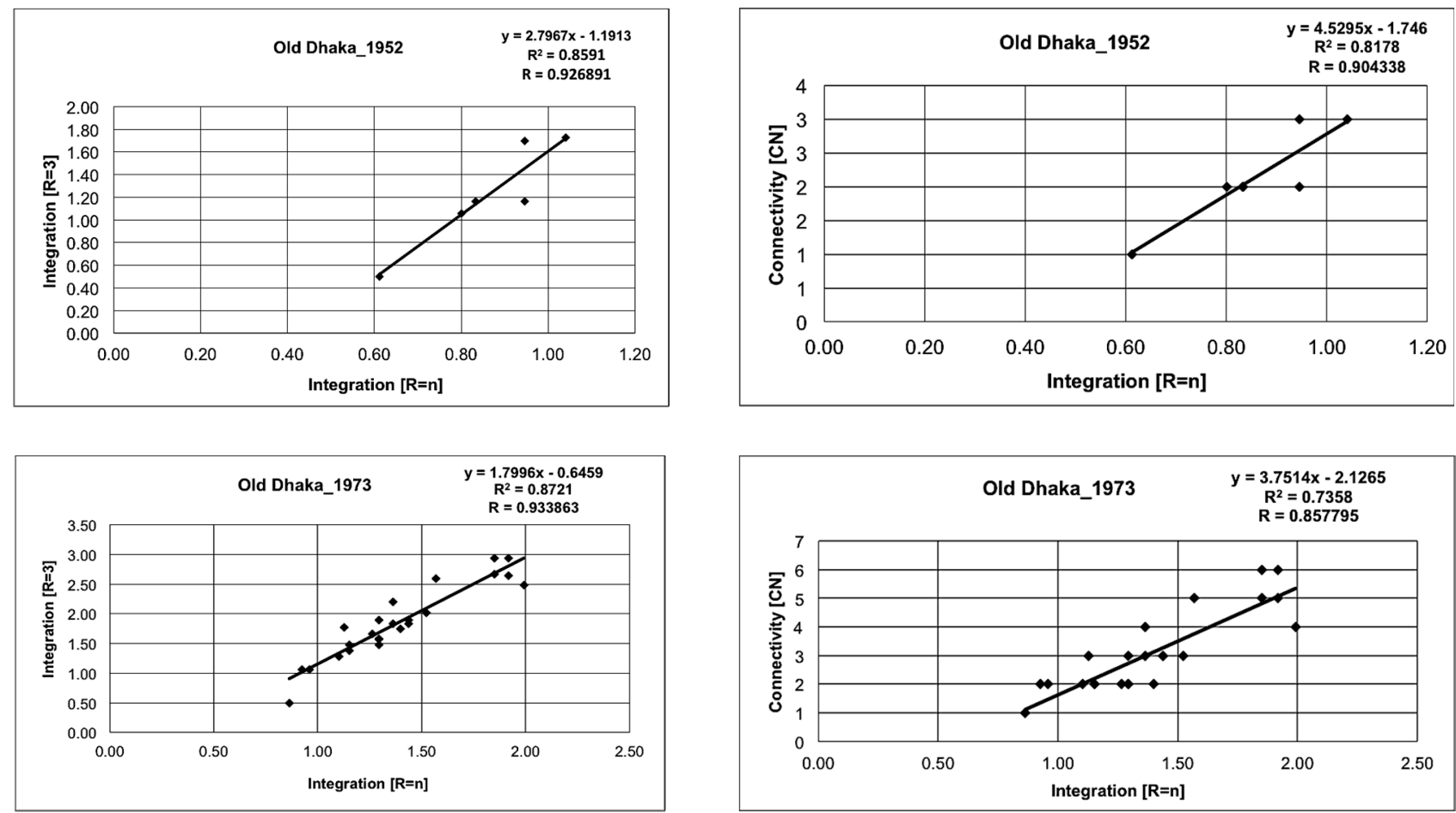
Figure 12. Cont.
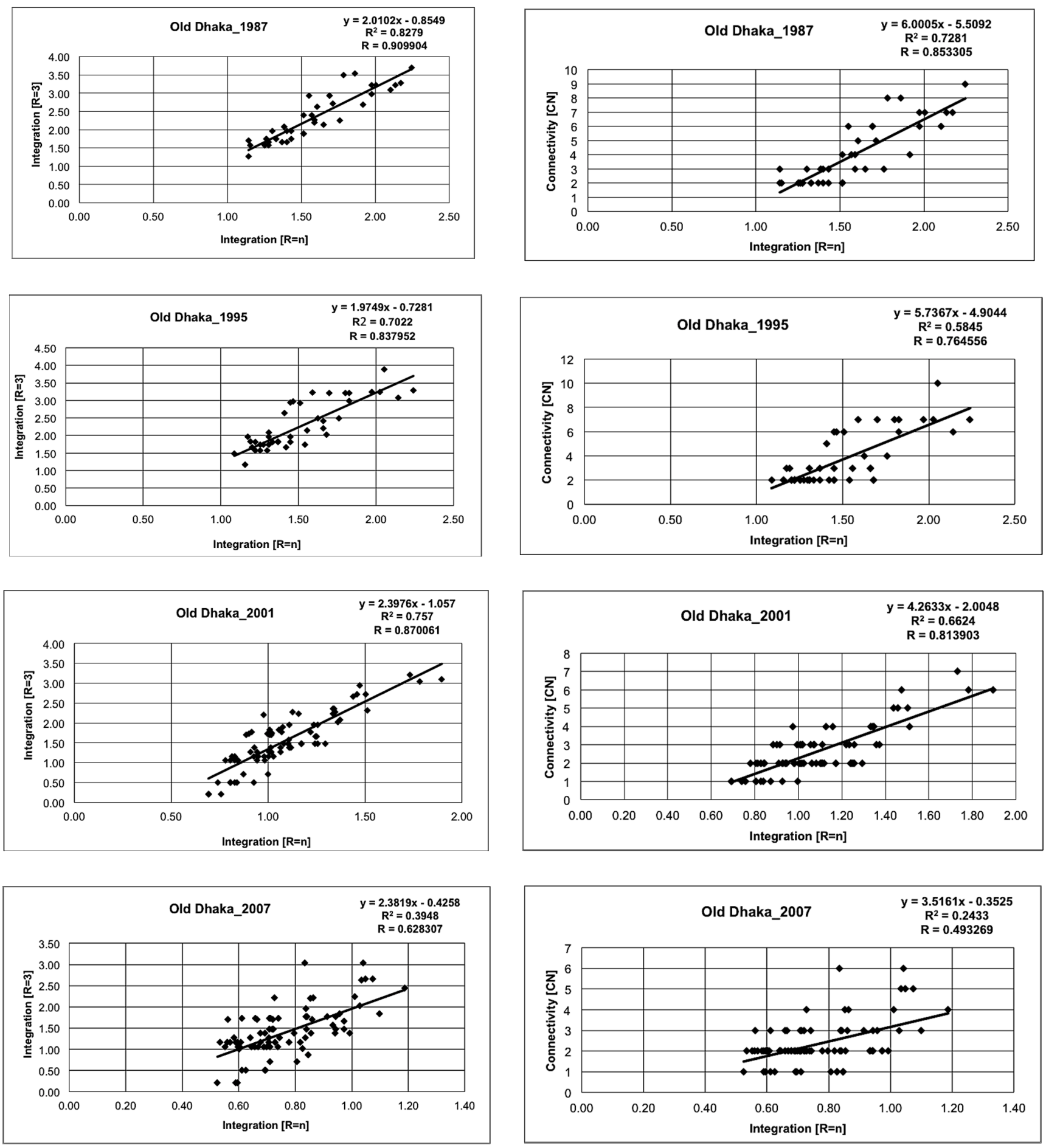

The global and local correlation ( $\mathrm{R} n-\mathrm{R} 3$ and $\mathrm{R} n-\mathrm{CN})$ is high, steady, and has a steep slope (Table 5 and Figure 13). The lower correlation values (Table 5) indicate that the local roads are much more segregated from the global ones and the global roads are more important in comparison to the local roads. In a planned residential area, the syntactic measures are relatively unchanged and have high values in all the phases. Higher values indicate that the street network is highly connective among each other. This is the basic morphological characteristic of a planned residential area like ward 19. 
Figure 13. Scatter of correlation between local and global measures (Rn-R3) and (Rn-CN) of ward 19 (Gulshan).
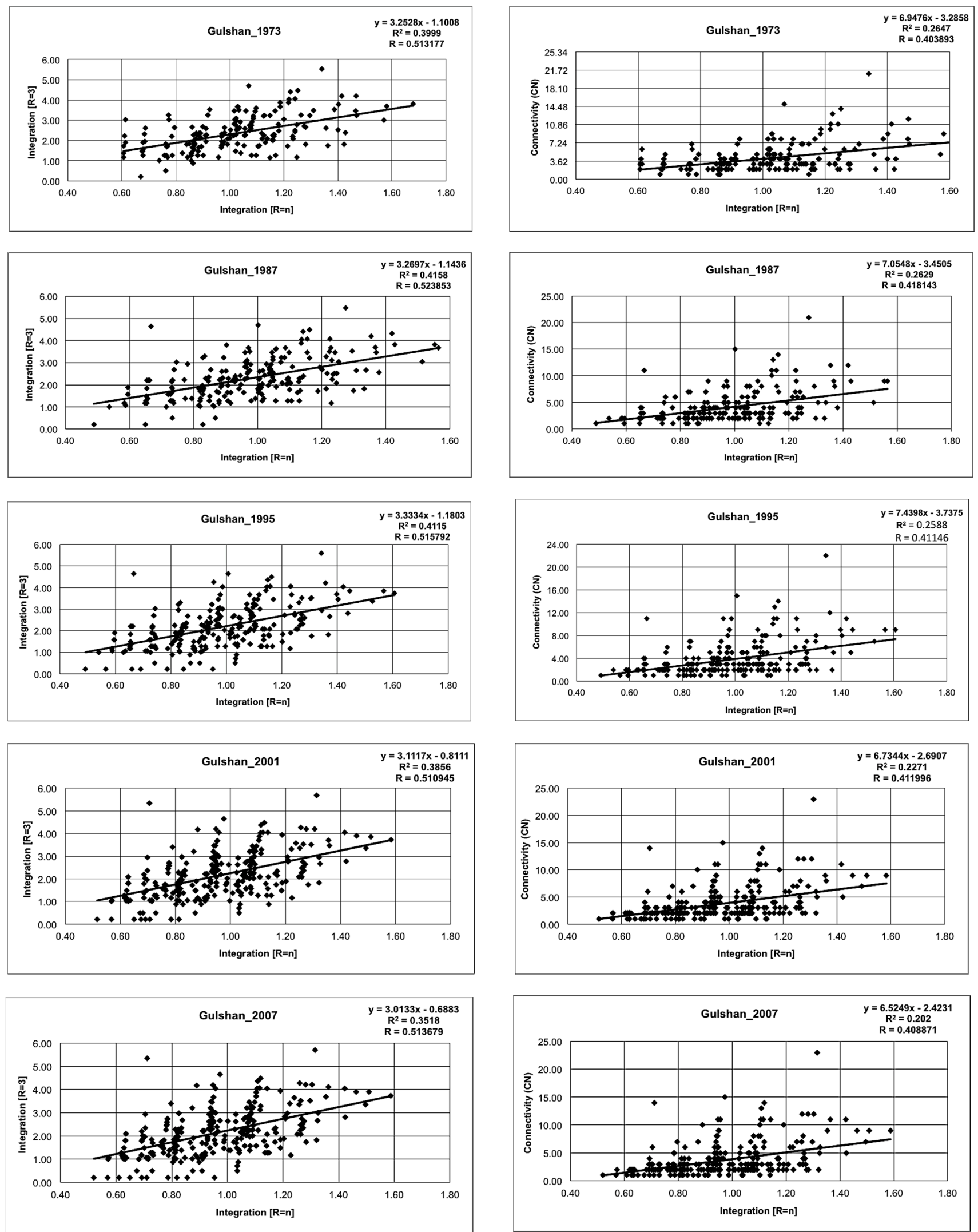
Figure 14. Scatter of correlation between local and global measures ( $\mathrm{R} n-\mathrm{R} 3)$ and $(\mathrm{R} n-\mathrm{CN})$ of ward 18 (Baridhara).
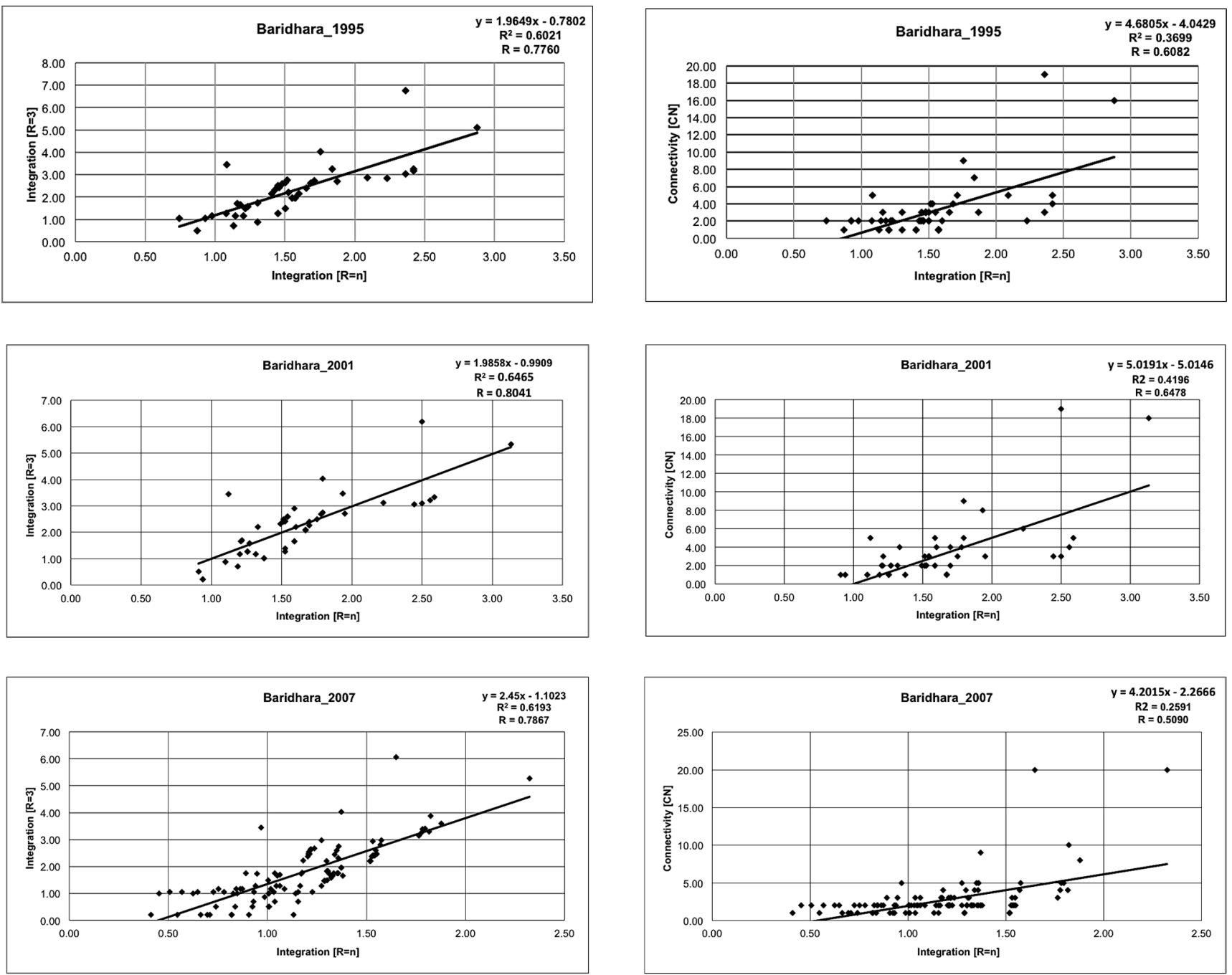

\subsubsection{Summary of Syntactic Analysis of Ward 18}

Throughout the years, the integration core consisted of Pragati Sharani/Biswa Road, Park Road, the United Nations (UN) Road, Baridhara Road, Dutabas (Embassy) Road, and few other roads of Baridhara (Road 3 and 7); and roads from Shahzadpur towards Gulshan-2 (Manarat International School Road, and other roads connecting Biswa Road with Shahzadpur) (Figure 8). Major administrative and commercial activities of ward 18 are also located along these roads. In all the three phases, the most connected roads are the Biswa Road, Park Road, and the UN Road (Figure 11). The average connectivity is found to be static (Table 3). The global and local integration values are found almost unchanged between 1995 and 2007, but both the values dropped noticeably in 2007 (Table 3).

It indicates that the local roads are segregated more in recent years. The "R $n$-R3" correlation remained almost unchanged over the years, but the correlation value of " $\mathrm{R} n-\mathrm{CN}$ " is found to be lower in 2007 (Table 6). The slope is found steeper for "Rn-R3" than for "Rn-CN" (Figure 14 and Table 6). This indicates that the rapid urban development along the unplanned streets of Shahzadpur, and Kalachadpur areas are affecting the planned residential characteristics of Baridhara area. It is also 
evident that, in recent times, Shahzadpur area expanded spontaneously, with many locally connective roads (Figure 11). For this reason, both the local integration and correlation of " $\mathrm{R} n$-CN" values are found as the lowest in comparison to 1995 and 2001 (Table 6).

\subsubsection{Summary of the Findings of the Syntactic Analyses}

Ward 72 (Old Dhaka) is nearly 400 years old [3]. It is assumed that there was no planning intervention during the shaping of this area. This is an organic settlement. On the other hand, ward 19 (Gulshan) is about 50 years old and a planned area. Lastly, ward 18 (nearly 30 years old) is a mixed type of settlement, where one can find both the planned and informally grown settlements. These three types of settlements are commonly visible in Dhaka City $[3,8]$. As it was not possible to analyze the morphological characteristics of the whole DMA, therefore, these three distinct types of settlements are taken into consideration to understand the urban planning interventions within the city. This article is not only comparing the three different areas, but also is trying to foresee the effects of the different interventions as taken by the local people or the concerned local authorities.

Research using the space syntax approach has shown how movement patterns are powerfully shaped by spatial layout; and how this relation shapes the evolution of the centers, and sub-centers that make cities livable [12]. A local area is said to be intelligible if its coefficient value is higher than the one of the global area [30]. The basic conclusion is that local integration can be used to study people's movements within an urban system. Accordingly, urban planners can foresee movement flows before the actual development of real urban systems by analyzing the morphological structure of the design plan using space syntax techniques [30].

In the case of ward 72, it is found that the intelligibility (both the global-local integration and global-local connectivity) is decreasing (Table 4 and Figure 12). It illustrates that the local roads are gradually gaining importance. This result is justified; as the population, commercial activities, and urbanization of this city are growing in course of time. In the case of ward 19, the global-local integration ( $\mathrm{R} n-\mathrm{R} 3)$ intelligibility is almost unchanged over the years (Table 5). This result also justifies the real-world scenario. Ward 19 (Gulshan) is planned, and the local planning authorities govern the land use interventions (e.g., the use of a plot as residential or commercial). This is why; although the street network is highly integrated, the intelligibility syntactic values are found unchanged. However, the global-local connectivity $(\mathrm{R} n-\mathrm{CN})$ or the relevant intelligibility is decreasing for ward 19 (Figure 13). This indicates that the local roads are becoming more important as the construction of buildings or infrastructure is taking place.

Finally, the "Rn-R3" of ward 18 is increasing and the "Rn-CN" is decreasing (Table 6 and Figure 14). This is because of the local areas are being segregated from the urban core, and the local roads are also gaining importance. Although some parts of ward 18 are planned (e.g., Baridhara), but the continuous growth of the unplanned urban sprawls in other parts (e.g., Shahzadpur and Kalachadpur areas) are causing the newly developed roads or areas being segregated from the global core. This is how; the results are showing distinct characteristics for the three different types of settlements that exist within DMA. The syntactic measures, as found in this article, are also reflecting the urban planning interventions as undertaken in different time periods; and the natural growth of the city's areas. This kind of urban morphological change analysis, in the light of history, can give proper directions on 
whether to plan an area or to let it grow spontaneously. Based on the results of this article, important decisions can be made for the future planning of Dhaka City.

\section{Discussions}

Space syntax provides an alternative vision and model of space for the representation of urban systems with GIS [9,30]. This article introduces the principles and modeling concepts of space syntax, and some of its main spatial parameters. It supports the computational modeling and analysis of a spatial configuration for urban planning. The analytical tool used in this research is an implementation of space syntax within a GIS platform, namely the "Axwoman3" prototype.

It is observed that on average, the syntactic values were found to be the highest for ward 72 , then ward 18, and ward 19 (Tables 1-6); respectively. Higher values indicate that there is a strong relation of connectivity among the global and local roads. The higher the connectivity and control, the higher the syntactic values. This means that the street network of Old Dhaka is much more connective than the other wards. This suggests that the indigenous settlements or organic parts of Dhaka City (e.g., ward 72) are most integrated in terms of road networks. The mixed-type areas (e.g., ward 18) are moderately integrated and connective, with syntactic values less than those for the organic settlements. The lowest syntactic values were found in the planned settlements (e.g., ward 19).

Syntactic analyses can reveal the roads of the area that are more connective or have higher control values. However, it is not possible to definitively ascertain the reasons behind the higher or lower values obtained. Higher correlation values indicate that both the global and local roads of an area are important, and that control and connectivity among the roads are also high [3]. For example, if an area shows high correlation values (e.g., Old Dhaka), it means the overall road network of the area is highly accessible. Sometimes the syntactic values are found higher in the later periods; this is because of the change of connectivity pattern or control value of the roads. The change may occur due to the greater connectivity of local roads, which can decrease the overall correlation values and vice versa.

\subsection{Nature of Integration Core}

It is believed that in a spatial configuration, as a consequence of the relative depth distribution (i.e., integration), the most integrated spaces in the system tend to attract certain types of land use that benefit from the concentration of people [31]. Thus, in general, the most integrated streets or core lines are the ones most used by people and also lined with important global function and local shops [3].

In Old Dhaka (ward 72), the integration of different phases is found mostly along the commercial interface and the integration core follows the pattern of linear commercial streets (e.g., Shakhari Bazaar). For the Gulshan and Baridhara areas; the core also followed the commercial hub, and other major administrative functional activities. Shankhari Bazaar (ward 72), Gulshan Avenue and Kamal Ataturk Avenue (ward 19), and Biswa Road (ward 18) are well known for city-scale commercial activities, and these roads also fall within the global integration core. 


\subsection{Connectivity of Street Network}

It is observed that a variation of road patterns existed in the study areas where different levels of streets are present in general. The configurational pattern of the selected areas exhibits a strong and defined order, where the system of primary axial lines contains high syntactic values. It was observed that the city-scale commercial and global functions are growing, along with key primary activities.

The local areas that grow along the secondary axes contain the locality-based social and commercial functions (e.g., ward 72). These secondary roads sometimes merge with the total city structure that creates its importance both locally and globally (e.g., ward 18). Finally the tertiary-level roads hold residential functions, which are segregated from city-scale commercial areas (e.g., ward 19).

\subsection{Global-Local Correlation}

In some cases, a strong global-local correlation exists (e.g., ward 72); while some areas are more locally integrated (e.g., ward 19). This pattern of relationship is supposed to be influenced by the land use of surrounding areas, whether residential or commercial. The correspondence between the local and global integration cores in the study areas is accompanied by a high statistical correlation. This indicates the degree to which there is a natural, and consistent relation through the structure of the grid; and sub-grid between scales of interaction $[3,9]$.

\subsection{Limitations and Future Research}

The main advantage of this kind of morphological analysis is the integration of space syntax into an advanced GIS environment to interpret the complex urban systems. The results of this research are based on the empirical, and syntactical analysis of Dhaka City. This is why; the outcome of this article or the conclusions drawn from the morphological analysis may only be applicable to Dhaka City. For other cities in Bangladesh or in any other countries of the world, the similar analysis can give different results. For example, the intelligibility values of a planned residential area in another city might be the highest. Moreover, it is important to collect the base maps of a certain area with appropriate street networks, because a detailed road network map is the prerequisite for drawing the axial maps; otherwise, the analyses can give abrupt results. Again, the different scales of the base maps can generate some errors. Another limitation of this research is that it has analyzed only three wards out of 92 to interpret the morphological change of DMA. Future research can consider analyzing the whole city, which might give some new insights.

Based on the shortcomings of this research, future research is suggested to compare at least two different cities in terms of urban morphological change; and to make sure that the street networks of the entire base maps are coherent, and visible in detail. Moreover, the maps should be produced in similar scale. Finally the researchers must ensure that the analysis of the historical growth of the city is done properly. This would help to minimize the possible errors, and getting more valid results, while analyzing the urban morphological change of a city using the space syntax technique.

Ratti (2004) already identified some inconsistencies in space syntax. He pointed out some limitations like not considering the dimensional property of streets, building heights, land use, and its sensitivity to boundary conditions [32]. Later Hillier and Penn (2004) tried to rebut the issues raised by 
Ratti (2004), but finally they agreed that current computational power will soon allow these things to be done much better [33]. Still, there is much confusion that needs to be solved while dealing with the space syntax. In general, numerous driving factors like political, socio-economic, cultural, and religious issues, etc., can form the shape, and size of a city. The urban form and morphology of a city deal with other anthropogenic and psychological issues as well.

Therefore, analyzing the change in urban morphology of a city, just by considering the axial street networks and movement patterns of the people, can raise more serious questions about the validity of space syntax. All these criticisms, as well as the limitations, should be taken into consideration in future research.

\section{Conclusions}

The present study on the morphological analysis of Dhaka City is based on three representative case study areas (wards 18, 19 and 72). The pilot study areas represent the three distinct types of urban settlements (indigenous, planned, and mixed) that exist within DMA. A space syntax-based analytical tool (Axwoman3) implemented in a GIS platform is used to analyze the urban morphological changes of the selected areas. The results show that the organic settlements (e.g., ward 72) are highly integrated both in terms of the local and global street network (lowest standard deviation values for local and global integration, with the highest intelligibility values), and these roads have more connectivity.

On the other hand, the planned settlements (e.g., ward 19) are least connective and integrated with the local and global roads (highest standard deviation values for the local and global integration, with the least intelligibility values). The mixed settlements (e.g., ward 18) lie in between the organic and mixed settlements. Therefore, in summary, it can be stated that the old, organic; and indigenous areas of Dhaka City are highly integrated, and functional. This scenario is the opposite in the case of the planned settlements. The mixed areas (combining both the planned and informal types) are moderately functional with higher syntactic values than the planned settlements. Moreover, in all the cases, the global integration core is found to be located near the commercial and administrative areas.

The results of this research are based on both the empirical and syntactical analyses of Dhaka City. The observations from this study may not apply to other cities of Bangladesh. It is important to collect the base maps of a certain area with appropriate street networks. Maps from different periods can have different levels of accuracy of systems of projection. Even after careful attempts to standardize the different maps, the residual discrepancies can affect the results of the analysis.

\section{Acknowledgments}

Bayes Ahmed is a Commonwealth Scholar funded by the UK government. This article is extracted from the undergraduate thesis, which was conducted by Bayes Ahmed and Rakibul Hasan in the Department of Urban and Regional Planning, Bangladesh University of Engineering and Technology (BUET), Dhaka, Bangladesh. K. M. Maniruzzaman was the primary supervisor of the thesis.

The authors would like to thank the Survey of Bangladesh and National Archives of Bangladesh for providing the historical base maps of Dhaka City. The authors are also grateful to the Asiatic Society of Bangladesh and Azim Buksh of "Dhaka Kendra" for providing necessary books, photographs, documents, and relevant articles. Finally the authors want to extend their gratitude to the three 
anonymous reviewers and the editors of ISPRS IJGI journal for their constructive comments that improved the quality of this paper.

\section{Author Contributions}

Bayes Ahmed performed all the relevant GIS analyses and produced the graphs related to the implementation of the space syntax method in the three wards $(18,19$ and 72$)$ in Dhaka City. He wrote the data collection, findings, discussions, and conclusions sections. He also prepared and edited this manuscript.

Rakibul Hasan wrote the introduction and methodology sections. He also collected the necessary maps from different organizations and digitized the relevant base maps.

K. M. Maniruzzaman developed the research proposal, supervised the whole work, and edited this article.

\section{Appendix}

Table A1. Historical growth of Dhaka City in population and area.

\begin{tabular}{ccc}
\hline Year & Total Population & Approximate Area (Square Miles) \\
\hline 1600 & --- & 1 \\
1640 & 200,000 & -- \\
1700 & 900,000 & 50 \\
1800 & 200,000 & 8 \\
1814 & 200,000 & -- \\
1824 & 300,000 & --- \\
1838 & 68,038 & -- \\
1867 & 51,636 & 8 \\
1872 & 69,212 & --- \\
1881 & 80,358 & -- \\
1891 & 83,358 & -- \\
1901 & 104,385 & 10 \\
1911 & 125,733 & 10 \\
1921 & 137,908 & 12 \\
1931 & 161,922 & 12 \\
1941 & 239,728 & 12 \\
$1951 *$ & 335,928 & 15 \\
$1961 *$ & 550,143 & 26 \\
$1974 *$ & $1,679,572$ & 40 \\
$1981 *$ & $3,430,311$ & 155.4 \\
$1991 *$ & $6,950,920$ & 522.34 \\
$1981 * *$ & $2,475,710$ & 50 \\
$1991 * *$ & $3,839,000$ & 54.5 \\
$2001 * *$ & $77,94,086$ & 140 \\
$2011 * *$ & $93,17,043$ & 360 \\
\hline
\end{tabular}

“---" Represents, data not available.

* Dhaka Statistical Metropolitan Area (DSMA); ** Dhaka City Corporation (DCC) and other urban areas. Source: Ahmed, Hasan and Ahmad (2008) [3]; Ahmed (2012) [5]; Ibrahim (2012) [34]; Ahmed (2011) [35]; and Ahmed (2014) [36]. 
Figure A1. Maps showing rapid urbanization in Dhaka Metropolitan Area (1989-2009). Source: Ahmed et al., 2013 [4].

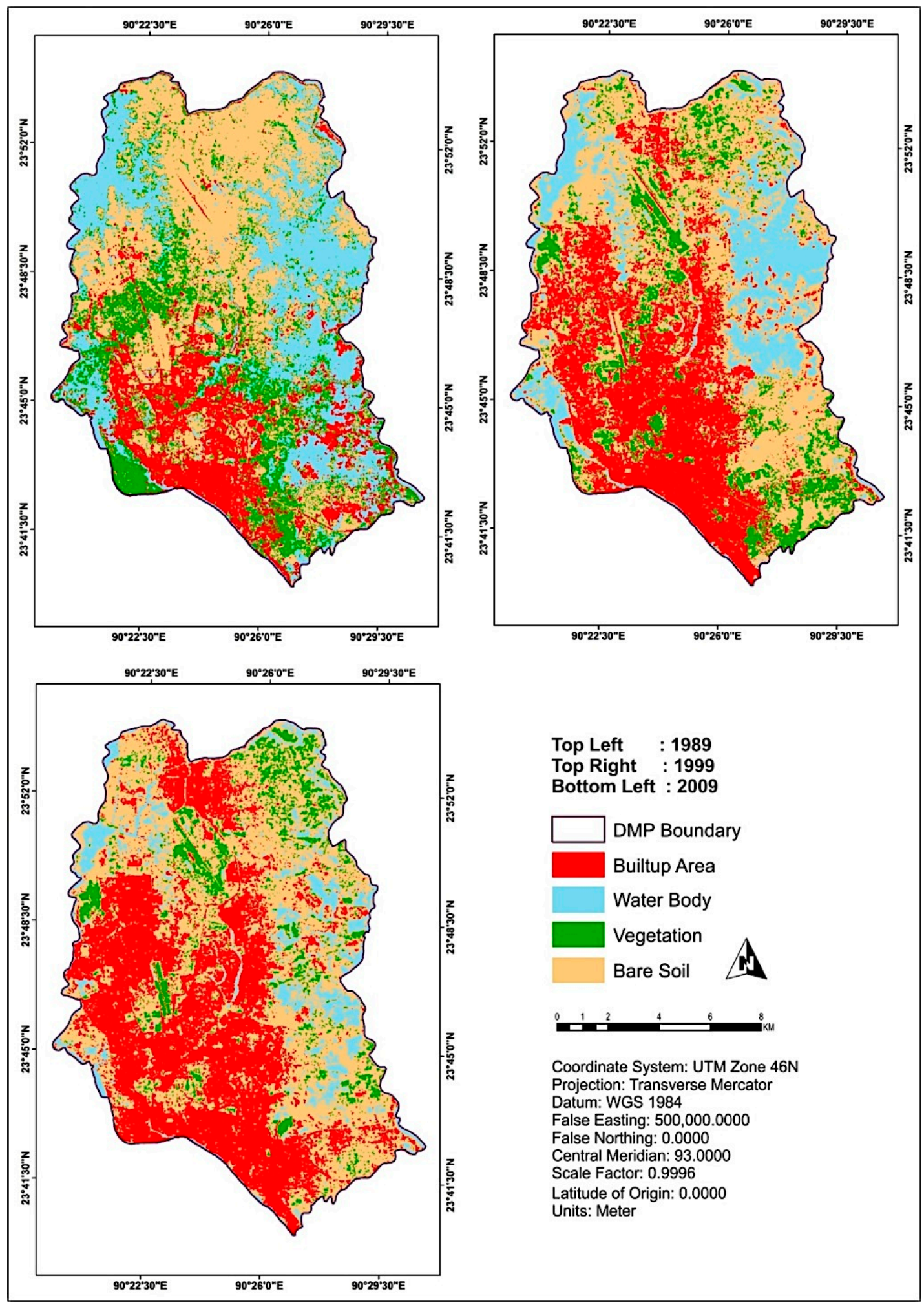


Figure A2. Base maps of ward 18 (Baridhara) for syntactic analysis (not to scale). Source: Survey of Bangladesh and Google Earth Image, 2007.

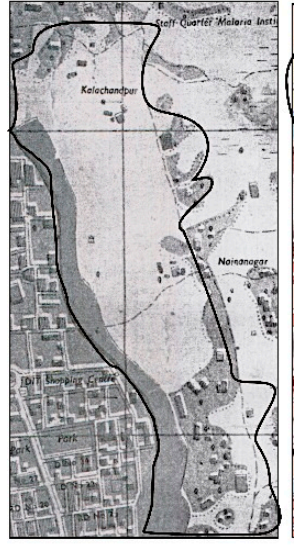

1973

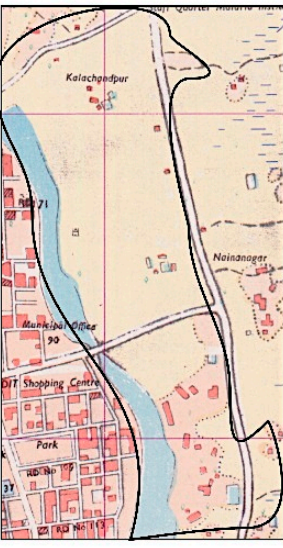

1987

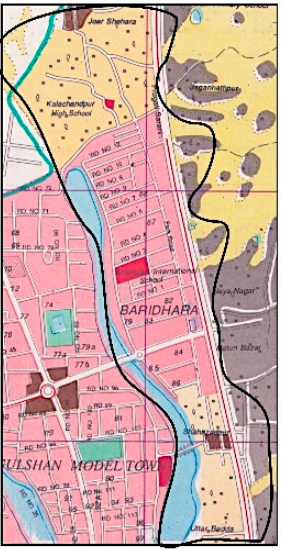

1995

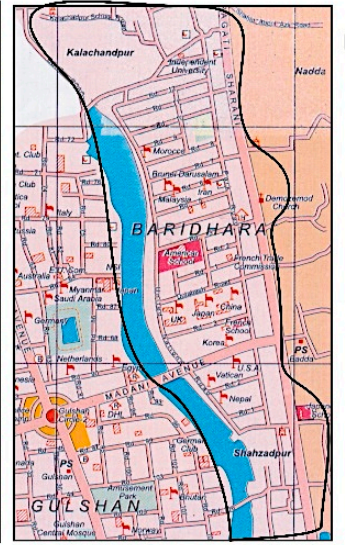

2001

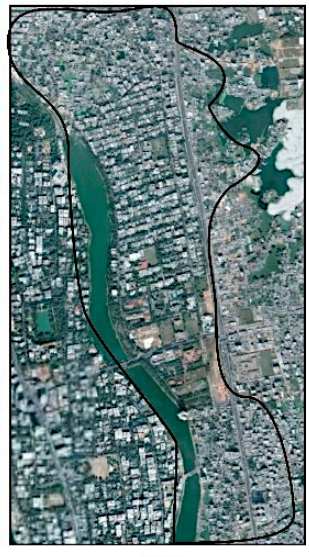

2007

Figure A3. Base maps of ward 19 (Gulshan) for syntactic analysis (not to scale). Source: Survey of Bangladesh and Google Earth Image, 2007.

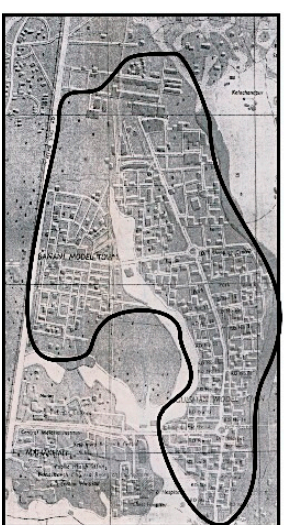

1973

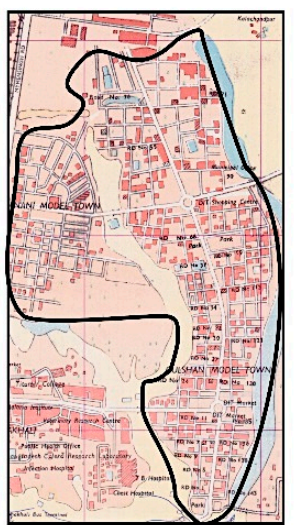

1987

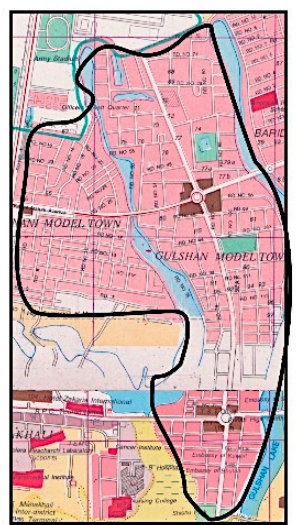

1995

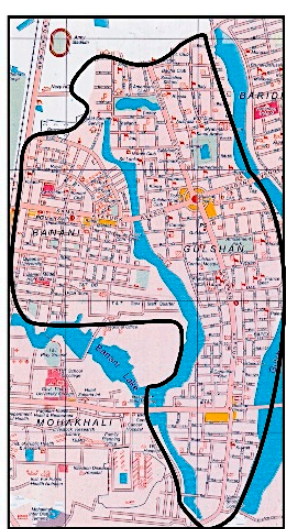

2001

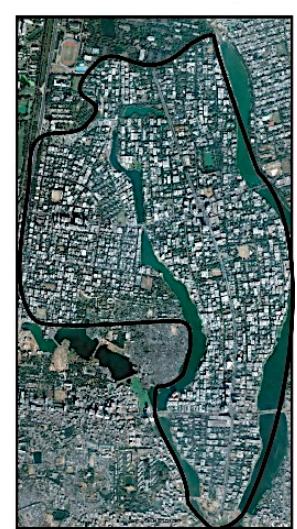

2007

Figure A4. Base maps of ward 72 (Old Dhaka) for syntactic analysis (not to scale). Source: Survey of Bangladesh and Google Earth Image, 2007.

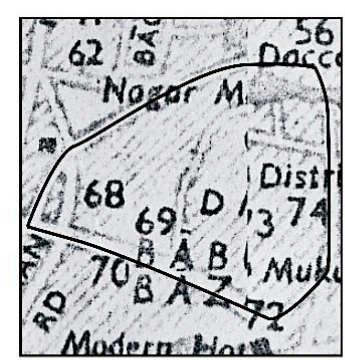

1952

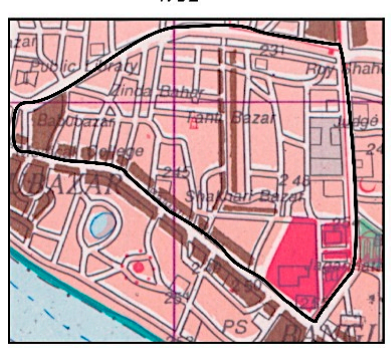

1995

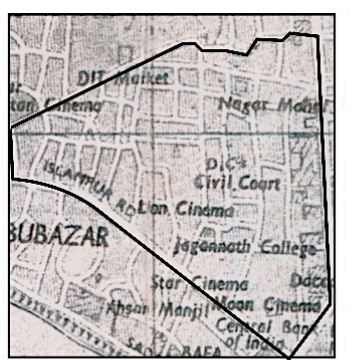

1973

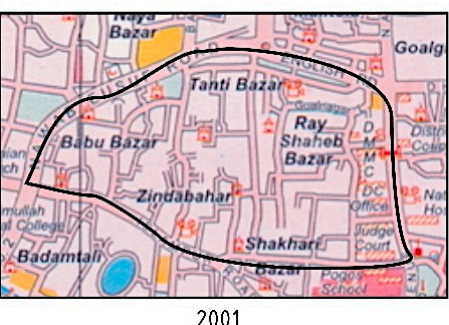

2001

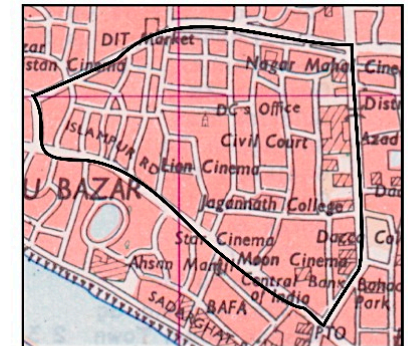

1987

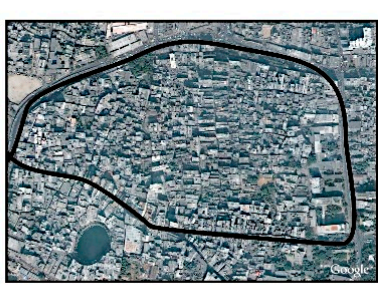

2007 


\section{Conflicts of Interest}

The authors declare no conflict of interest.

\section{References}

1. Ahmed, B.; Ahmed, R. Modeling urban land cover growth dynamics using multi-temporal satellite images: A case study of Dhaka, Bangladesh. ISPRS Int. J. Geo-Inf. 2012, 1, 3-31.

2. Ahmed, B.; Raj, M.R.H.; Maniruzzaman, K.M. Morphological change of Dhaka City over a period of 55 years: A case study of two wards. J. Bangladesh Inst. Plan. 2009, 2, 30-38.

3. Ahmed, B.; Hasan, R.; Ahmad, S. A Case Study of the Morphological Change of Four Wards of Dhaka City over the Last 60 Years (1947-2007). Undergraduate Thesis, Bangladesh University of Engineering and Technology, Dhaka, Bangladesh, 2008.

4. Ahmed, B.; Kamruzzaman, M.; Zhu, X.; Rahman, M.S.; Choi, K. Simulating land cover changes and their impacts on land surface temperature in Dhaka, Bangladesh. Remote Sens. 2013, 5, 5969-5998.

5. Ahmed, B. Traffic Accident Study in Dhaka City (2007-2011); DCC-S4B; Clean Air and Sustainable Environment Project, Dhaka South City Corporation: Dhaka, Bangladesh, 2012.

6. Ahmed, S.U. Dhaka Past Present Future, 1st ed.; The Asiatic Society of Bangladesh: Dhaka, Bangladesh, 1991.

7. Chowdhury, A.M. Dhaka, 2nd ed.; Asiatic Society of Bangladesh: Dhaka, Bangladesh, 2012.

8. Islam, Z. High-Rise Residential Development in Dhaka City: Evolution of the New Form. Master's Thesis, Bangladesh University of Engineering and Technology, Dhaka, Bangladesh, 2003.

9. Nilufar, F. The Spatial and Social Structuring of Local Areas in Dhaka City-A Morphological Study of the Urban Grid with Reference to Neighbourhood Character within Naturally-Grown Areas. Ph.D. Thesis, University College London, London, UK, 1997.

10. Hashem, M. Trends of Development in Dhanmondi Residential Area of Dhaka City. Master's Thesis, Bangladesh University of Engineering and Technology, Dhaka, Bangladesh, 2001.

11. Moudon, A.Y. Urban morphology as an emerging interdisciplinary field. J. Urban Morphol. 1997, 1, 3-10.

12. Space Syntax Laboratory. Available online: http://www.bartlett.ucl.ac.uk/graduate/research/space/ space-syntax (accessed on 9 May 2014).

13. Hillier, B.; Hanson, J. The Social Logic of Space, 1st ed.; Cambridge University Press: Cambridge, UK, 1984.

14. Jiang, B.; Claramunt, C. Integration of space syntax into GIS: New perspectives for urban morphology. Trans. GIS 2002, 6, 295-309.

15. Önder, D.E.; Gigi, Y. Reading urban spaces by the space-syntax method: A proposal for the south haliç region. Cities 2010, 27, 260-271.

16. Foltête, J.-C.; Piombini, A. Urban layout, landscape features and pedestrian usage. Landsc. Urban Plan. 2007, 81, 225-234. 
17. Kim, H.-K.; Sohn, D.W. An analysis of the relationship between land use density of office buildings and urban street configuration: Case studies of two areas in Seoul by space syntax analysis. Cities 2002, 19, 409-418.

18. Giannopoulou, M.; Roukounis, Y.; Stefanis, V. Traffic network and the urban environment: An adapted space syntax approach. Procedia Soc. Behav. Sci. 2012, 48, 1887-1896.

19. Duan, Z.-Y.; Wang, Q. Road network analysis and evaluation of Huizhou city based on space syntax. In Proceedings of the 2009 International Conference on Measuring Technology and Mechatronics Automation, Zhangjiajie, China, 11-12 April 2009; pp. 579-582.

20. Zhan, Q.; Zhou, J.; Xiao, Y. Applying space syntax in large polycentric city. In Proceedings of the 2009 IEEE International Conference on Geoinformatics, Fairfax, VA, USA, 12-14 August 2009; pp. 1-6.

21. Tariq, T.; Nilufar, F. Integrating the recreational spaces of Rangpur City Corporation, Bangladesh. In Proceedings of the 2013 International Space Syntax Symposium, Seoul, Korea, 31 October-3 November 2013; Kim, Y.O., Park, H.T., Seo, K.W., Eds.; Sejong University Press: Seoul, Korea, 2013.

22. Karimi, K.; Vaughan, L. An evidence-based approach to designing new cities: The English new towns revisited. In Explorations in Urban Design: An Urban Design Research Primer; Carmona, M., Ed.; Ashgate Publishing: Ashgate, Surrey, UK, 2014; pp. 261-276.

23. Wang, H.; Shi, S.; Rao, X. A study of urban density in Shenzhen: The relationship between street morphology, building density and land use. In Proceedings of the Ninth International Space Syntax Symposium, Seoul, Korea, 31 October-3 November 2013; Kim, Y.O., Park, H.T., Seo, K.W., Eds.; Sejong University Press: Seoul, Korea, 2013.

24. Mohamed, A.A.; Nes, A.V.; Salheen, M.A.; Kohlert, C.; Schwander, C. The socio-economic implications of the spatial configuration in greater Cairo metropolitan area. In Proceedings of the 2013 International Space Syntax Symposium, Seoul, Korea, 31 October-3 November 2013; Kim, Y.O., Park, H.T., Seo, K.W., Eds.; Sejong University Press: Seoul, Korea, 2013.

25. Law, S.; Karimi, K.; Penn, A.; Chiaradia, A. Measuring the influence of spatial configuration on the housing market in metropolitan London. In Proceedings of the 2013 International Space Syntax Symposium, Seoul, Korea, 31 October-3 November 2013; Kim, Y.O., Park, H.T., Seo, K.W., Eds.; Sejong University Press: Seoul, Korea, 2013.

26. Castillo, M.M. Urban patterns and disaster risk: The informal city on the hills. In Proceedings of the 2013 International Space Syntax Symposium, Seoul, Korea, 31 October-3 November 2013; Kim, Y.O., Park, H.T., Seo, K.W., Eds.; Sejong University Press: Seoul, Korea, 2013.

27. Ferdous, F. A Morphological Analysis of Indigenous Spatial Pattern in Old Dhaka with Particular Emphasis on Cultural Spaces. Master's Thesis, Bangladesh University of Engineering and Technology, Dhaka, Bangladesh, 2007.

28. Kubat, A.S. The morphological history of Istanbul. J. Urban Morphol. 1999, 3, 28-41.

29. Hillier, B.; Penn, A. Dense civilizations: The shape of cities in the 21st century. J. Appl. Energy 1992, 43, 41-66.

30. Jiang, B.; Claramunt, C.; Klarqvist, B. Integration of space syntax into GIS for modelling urban spaces. Int. J. Appl. Earth Obs. Geoinf. 2000, 2, 161-171. 
31. Hillier, B. Space is the Machine: A Configurational Theory of Architecture; Cambridge University Press: London, UK, 2007.

32. Ratti, C. Urban texture and space syntax: Some inconsistencies. Environ. Plan. B Plan. Des. 2004, 31, 487-499.

33. Hillier, B.; Penn, A. Rejoinder to Carlo Ratti. Environ. Plan. B Plan. Des. 2004, 31, 501-511.

34. Ibrahim, R. Community Report: Dhaka Zila. In Population and Housing Census 2011; Ministry of Planning, Ed.; Bangladesh Bureau of Statistics: Dhaka, Bangladesh, 2012; pp. 8-12.

35. Ahmed, B. Urban Land Cover Change Detection Analysis and Modeling Spatio-Temporal Growth Dynamics Using Remote Sensing and GIS Techniques: A Case Study of Dhaka, Bangladesh. Master's Thesis, University of New Lisbon, Lisbon, Portugal, 2011.

36. Ahmed, B. Contemporary issues and priorities in addressing the road safety problems of Dhaka Metropolitan Area, Bangladesh. J. Bangladesh Inst. Plan. 2014, 6, 103-118.

(C) 2014 by the authors; licensee MDPI, Basel, Switzerland. This article is an open access article distributed under the terms and conditions of the Creative Commons Attribution license (http://creativecommons.org/licenses/by/4.0/). 